\title{
The Influence of IL-10 and TNFa on Chondrogenesis of Human Mesenchymal Stromal Cells in Three-Dimensional Cultures
}

\author{
Michal Jagielski, Johannes Wolf, Ulrike Marzahn, Anna Völker, Marion Lemke, Carola Meier, \\ Wolfgang Ertel, Owen Godkin, Stephan Arens ${ }^{\dagger}$ and Gundula Schulze-Tanzil ${ }^{\dagger} * *$ \\ Department for Orthopedic, Trauma and Reconstructive Surgery, Charité-Universitätsmedizin Berlin, \\ Campus Benjamin Franklin, 14195 Berlin, Garystrasse 5, Germany; \\ E-Mails: michal.jagielski@charite.de (M.J.); tgjpw@web.de (J.W.); umarzahn@gmail.com (U.M.); \\ anna.voelker@medizin.uni-leipzig.de (A.V.); marion.lemke@charite.de (M.L.); \\ carola.meier@charite.de (C.M.); wolfgang.ertel@charite.de (W.E.); \\ owen.godkin@gmail.com (O.G.); stephan.arens@charite.de (S.A.) \\ $\dagger$ These authors contributed equally to this work. \\ * Author to whom correspondence should be addressed; E-Mail: gundula.schulze-tanzil@charite.de; \\ Tel.: +49-30-450-552-385; Fax: +49-30-450-552-985.
}

Received: 29 June 2014; in revised form: 25 August 2014 / Accepted: 2 September 2014 /

Published: 9 September 2014

\begin{abstract}
Chondrogenic differentiated mesenchymal stromal cells (MSCs) are a promising cell source for articular cartilage repair. This study was undertaken to determine the effectiveness of two three-dimensional (3D) culture systems for chondrogenic MSC differentiation in comparison to primary chondrocytes and to assess the effect of Interleukin (IL)-10 and Tumor Necrosis Factor (TNF) $\alpha$ on chondrogenesis by MSCs in 3D high-density (H-D) culture. MSCs were isolated from femur spongiosa, characterized using a set of typical markers and introduced in scaffold-free H-D cultures or non-woven polyglycolic acid (PGA) scaffolds for chondrogenic differentiation. H-D cultures were stimulated with recombinant IL-10, TNF $\alpha, \mathrm{TNF} \alpha+$ IL-10 or remained untreated. Gene and protein expression of type II collagen, aggrecan, sox 9 and TNF $\alpha$ were examined. MSCs expressed typical cell surface markers and revealed multipotency. Chondrogenic differentiated cells expressed cartilage-specific markers in both culture systems but to a lower extent when compared with articular chondrocytes. Chondrogenesis was more pronounced in PGA compared with H-D culture. IL-10 and/or TNF $\alpha$ did not impair the chondrogenic differentiation of MSCs. Moreover, in most of the investigated samples,
\end{abstract}


despite not reaching significance level, IL-10 had a stimulatory effect on the type II collagen, aggrecan and TNF $\alpha$ expression when compared with the respective controls.

Keywords: bone-marrow MSC; three-dimensional culture; articular chondrocytes; chondrogenesis; IL-10; TNF $\alpha$

\section{Introduction}

Cartilage injury remains still an orthopedic challenge, since mature cartilage has only a limited capacity for intrinsic repair. A major restriction for cell-based strategies suitable for improving cartilage repair, such as matrix assisted chondrocyte transplantation (MACT), are limited in their accessibility of autologous cartilage for chondrocyte isolation and in vitro expansion as well as donor site morbidity. The clinical outcomes are still unsatisfying [1,2]. Mesenchymal stromal cells (MSCs) are an accessible cell source in the body capable for chondrogenic differentiation with low donor site morbidity and hence, could be a promising approach for articular cartilage repair. Osteochondral defects are usually covered by MSCs which emigrate from the bone marrow cavities into the defect and start chondrogenic differentiation [3].

However, effective, pure and permanent chondrogenic differentiation of MSCs still remains a challenge [4,5].

The role of particular cytokines in chondrogenic MSC differentiation is mostly unclear. Cartilage injury can lead to an inflammatory milieu and the development of osteoarthritis (OA) [6]. Pro-inflammatory cytokines such as Tumor Necrosis Factor (TNF) $\alpha$ play a crucial role in the pathogenesis of OA [7]. Whereas the chondrogenic differentiation of MSCs is inhibited by TNF $\alpha$ and Interleukin (IL)-1 $\beta$ involving the NF- $\mathrm{BB}$ pathway [8], TNF $\alpha$ is known to induce proliferation and migration of MSCs [9]. MSCs can easily be isolated, extensively and rapidly be expanded while maintaining their chondrogenic differentiation potential. Therefore, large cell numbers can be obtained for therapeutic use, whereby their immunosuppressive effects might be interesting in arthritis therapy [10].

MSCs exert their immunomodulatory effects by expressing IL-10 and furthermore enhancing its expression within local tissue [11-13]. IL-10 is a typical anti-inflammatory cytokine [14]. Its over-expression by MSC has been established as a tool to utilize their immunosuppressive potential, e.g., to suppress acute graft-versus-host disease $[14,15]$. Whether IL-10 is a valuable tool in OA therapy remains unclear.

It is crucial to develop an effective method of MSC cultivation that allows a pure differentiation towards the selected mesenchymal lineage. A challenging approach in chondrogenic differentiation of MSCs can be the use of 3D cultures. Most commonly used are the pellet cultures [16,17]. To optimize this process, some researchers developed different $3 \mathrm{D}$ cultures consisting of a cell aggregate on a porous membrane $[4,18]$. Another interesting approach to achieve chondrogenic differentiation is the application of MSCs on polyglycolic acid (PGA). PGA is a resorbable polymer that can already be found in clinical use $[19,20]$. PGA scaffolds may enhance the repair of cartilage defects and are able to induce chondrogenic differentiation of MSCs [21,22]. Several mediators such as Transforming Growth Factor (TGF)- $\beta 1$ and $-\beta 3$ are known to induce effective chondrogenic differentiation of MSCs [18,23-25]. 
The aim of the present study was to determine the effectiveness of a scaffold-free and a scaffold-associated 3D culture system for chondrogenic MSC differentiation in comparison to primary chondrocytes and to gain a first insight into the impact of IL-10 and TNF $\alpha$ on chondrogenic differentiation of MSCs.

\section{Results}

\subsection{Results of Mesenchymal Stromal Cell (MSC) Characterization}

More than $92 \%$ of isolated plastic adherent cells from all donors expressed CD29 ( $\beta 1$-integrin), CD44 (hyaluronan receptor) and CD90 (thymocyte differentiation antigen 1) and less than 8\% expressed the leukocyte surface proteins CD3, CD4, CD8, CD14 and the hematopoetic cell marker CD34. The CD106 was expressed on $44.13 \%$ of all isolated cells (Figure 1). In agreement with the flow cytometrical results typical surface marker expression such as CD29, CD44 and CD90 could be depicted on the undifferentiated MSCs and localized using immunofluorescence labelling (Figure 2A-I). The CD34 expression on the MSCs was weak compared with the endothelial cell line (PAEICKR, positive control, Figure $2 \mathrm{~F}_{2}$ ). The endothelial cell line expressed only very weakly CD44 and CD90 (Figure $2 \mathrm{G}_{2}, \mathrm{H}_{2}$ ).

Figure 1. Characterization of mesenchymal stromal cells (MSCs) surface marker expression (passages 4-6) using flow cytometry. The isolated and adherent MSCs (cultured expanded for at least 4 passages) were tested for both, negative (CD3, CD4, CD8, CD14) $(n=5)$ and positive (CD29, CD44, CD90) markers $(n=10)$ using flow cytometry. The percentage of MSCs positive for the respective marker is shown (A); Less than a half of the MSCs were positive for the questionable surface marker CD106 $(n=10)$. The majority of the adherent MSCs was CD34 negative $(n=10)$ and negative for leukocyte surface proteins. The histograms of surface marker expression by MSCs of a representative donor are shown $\left(\mathbf{B}_{1}-\mathbf{B}_{5}\right)$.

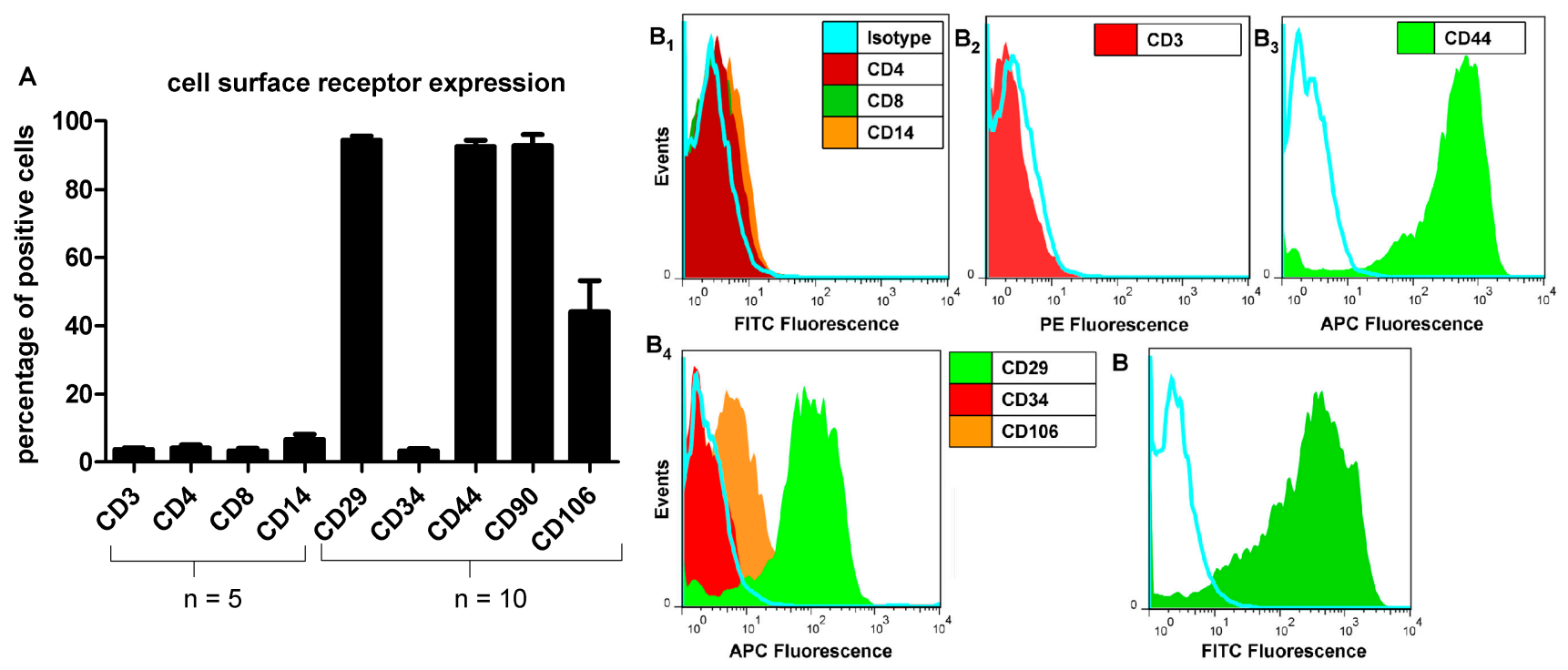


Figure 2. Characterization of MSCs surface marker expression (passages 4-6) using fluorescence microscopy. Surface markers such as leukocyte surface proteins CD3 (A); CD4 (B); CD8 (C); CD14 (D); cell adhesion protein CD29 (E); endothelial cell marker

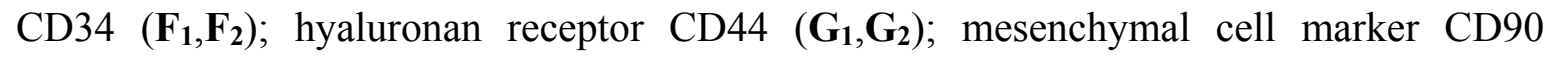
$\left(\mathbf{H}_{1}, \mathbf{H}_{2}\right)$; and CD106 (I) are depicted by immunofluorescence microscopy (green). Cells of the human endothelial cell line PAEICKR were immunolabelled for CD34 $\left(\mathbf{F}_{2}\right)$, CD44 (G) and CD90 $\left(\mathbf{H}_{2}\right)$ as a control. Cell nuclei were counterstained using 4',6-diamidino2-phenylindole (DAPI, blue). Scale bars $=50 \mu \mathrm{m}$.
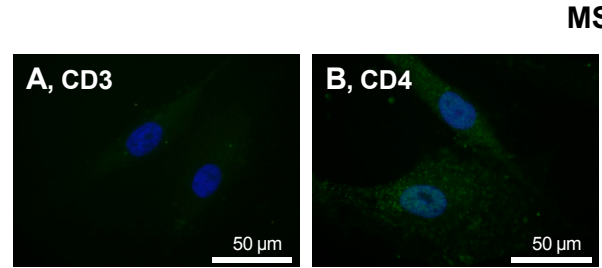

\section{MSCs}
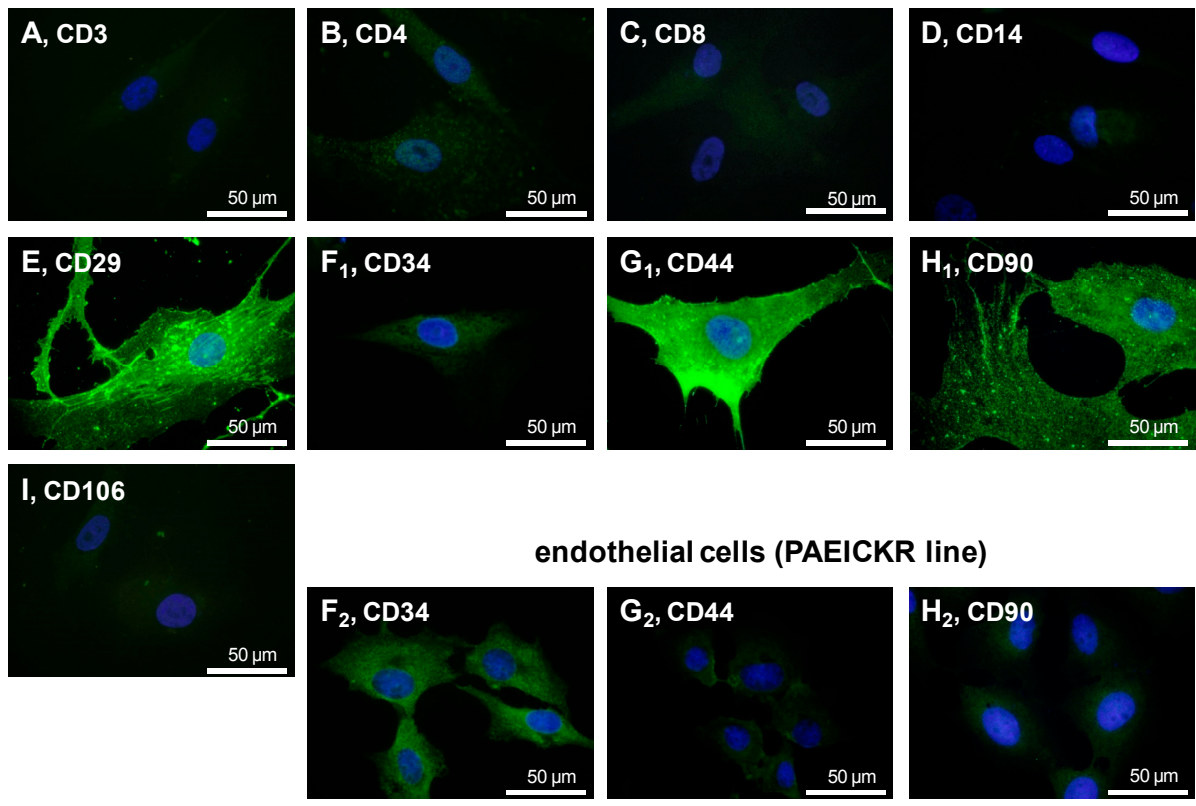

\section{endothelial cells (PAEICKR line)}
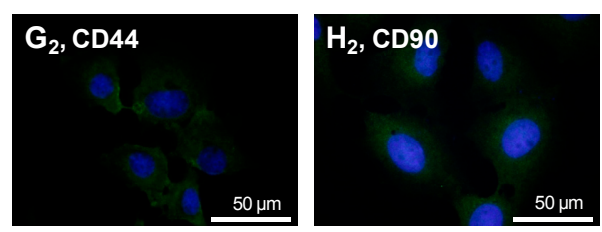

\subsection{Multipotency of MSCs}

Undifferentiated MSCs revealed a flattened and multipolar cell shape (Figure 3A). Chondrogenic differentiated cells formed 3D cell clusters when cultured in monolayer (not shown) and expressed typical cartilage markers such as type II collagen and sulfated glycosaminoglycans in H-D culture and PGA scaffold culture after 14 days. In contrast to undifferentiated MSCs (Figure 3A), adipogenically differentiated cells revealed multiple fat vacuoles after 21-28 days (Figure 3B-D) which were oil red positive (Figure 3D). Osteogenic differentiated cells became granulated and had a mostly bipolar shape (Figure 3C,E,G) compared to undifferentiated cells. Compared to adipogenic cells they were (Figure 3F) von Kossa positive (Figure 3G).

\subsection{IL-10 and IL-10 Receptor- $\alpha$ Expression}

Undifferentiated MSCs cultivated in monolayer culture for at least 3 passages revealed synthesis of IL-10. In addition IL-10 was detectable in the cytoplasm and in various cases in long cellular cytoplasmic extensions in cell-cell contact areas. The IL-10 receptor (IL-10R) $\alpha$ chain could also be detected using specific antibodies revealing a cytoplasmic distribution (Figure 4A-D). In contrast to IL-10R $\beta$ chain which is also a component in other IL-10 family cytokine receptors the $\alpha$ chain is specific for IL-10 signaling. 
Figure 3. Adipogenic and osteogenic differentiated MSCs. Invert microscopical images of undifferentiated (A), adipogenic $(\mathbf{B}, \mathbf{D}, \mathbf{F})$ and osteogenic $(\mathbf{C}, \mathbf{E}, \mathbf{G})$ differentiated MSCs in monolayer culture. The cells were adipogenically and osteogenically differentiated for 21 days. Adipogenic differentiated cells revealed multiple fat vacuoles $(\mathbf{B}, \mathbf{D})$ which were red after oil red staining (D, arrows). Osteogenic differentiation of MSCs led to granulated elongated cells $(\mathbf{C}, \mathbf{E}, \mathbf{G})$ which were von Kossa positive $(\mathbf{G})$ and formed clusters of extracellular matrix deposits $(\mathbf{C}, \mathbf{G}$, arrows). Images of a representative experiment are shown. Scale bars $=200 \mu \mathrm{m}$.

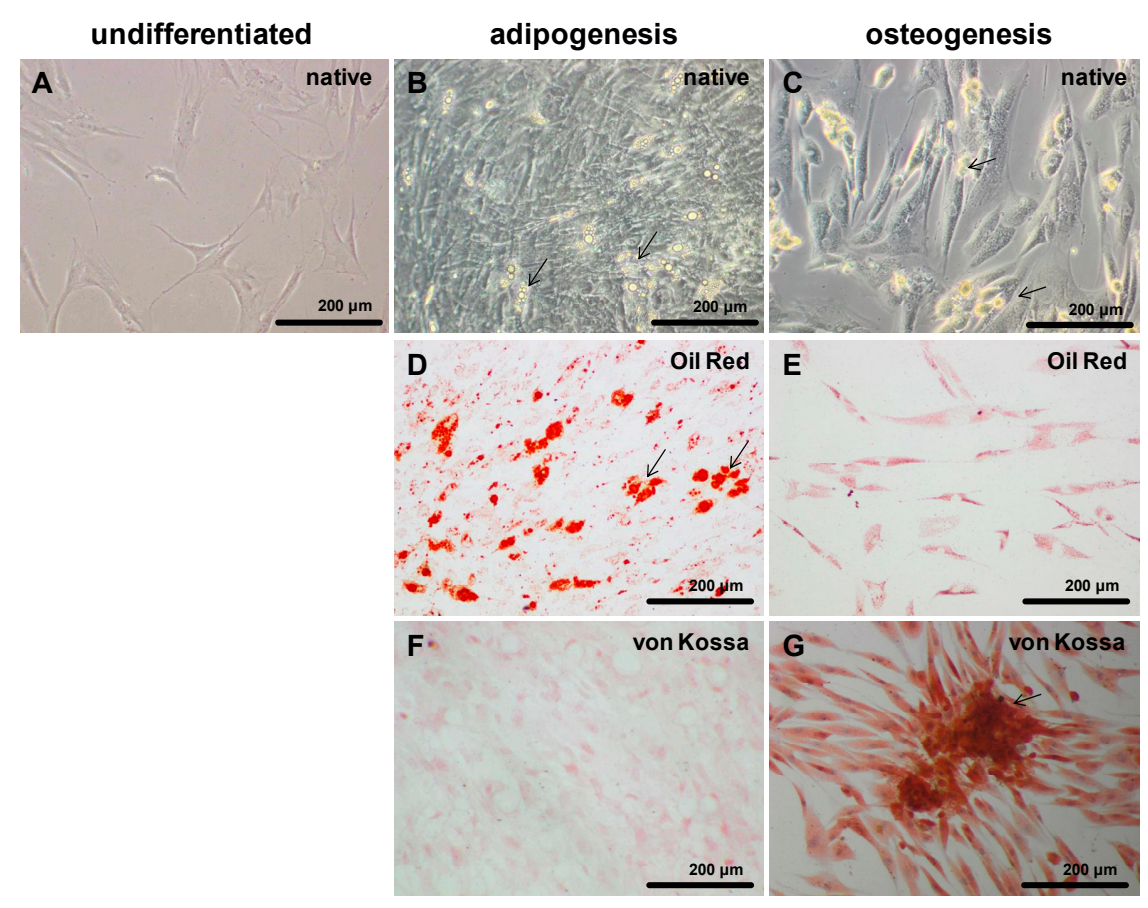

Figure 4. IL-10 and IL-10R $\alpha$ expression in undifferentiated MSCs. Undifferentiated MSCs were cultured for at least 3 passages in monolayer culture and immunolabelled with IL-10 (A) or IL-10R (C) specific antibodies or respective isotype controls (B,D) and Alexa-488 coupled secondary antibodies (green). Cell nuclei were counterstained using DAPI (blue). A representative experiment of 4 independent tests with cells of different donors is shown. Scale bars $=50 \mu \mathrm{m}$.
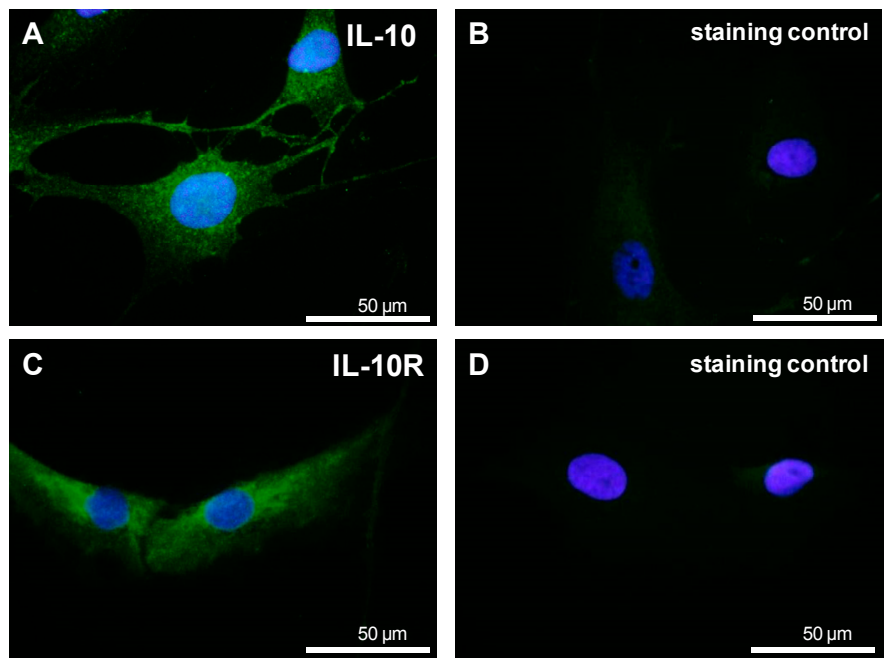
The MSCs showed immunoreactivity of STAT3. In some cells of the population a translocation of STAT3 in response to the short time treatment with IL-10 was detectable (Figure 5). Cells depicted only a faint STAT1 immunoreactivity and very few cells revealed nuclear STAT1 staining in response to IL-10 treatment.

Figure 5. STAT3 and STAT1 expression in undifferentiated human MSCs. Undifferentiated MSCs were seeded (third passage) for $24 \mathrm{~h}$ on cover slips, serum starved and treated with $10 \mathrm{ng} / \mathrm{mL}$ recombinant IL-10 or remained untreated (control). Subsequently, the cover slips with MSCs were immunolabelled either with STAT3 $\left(\mathbf{A}_{1}-\mathbf{A}_{4}\right)$ or STAT1 $\left(\mathbf{B}_{1}-\mathbf{B}_{4}\right)$ specific antibodies and Alexa-Fluor ${ }^{\circledR} 488$ coupled secondary antibodies (green). As a staining control the primary antibody was omitted $\left(\mathbf{C}_{1}-\mathbf{C}_{4}\right)$. Cell nuclei were counterstained using DAPI (blue). The cytoskeleton of the MSCs (also in the staining controls) is depicted using phalloidin-555 staining. A representative experiment of 2 tests with cells of 2 different donors is shown by confocal laser scanning microscopy. Scale bar $=100 \mu \mathrm{m}$.

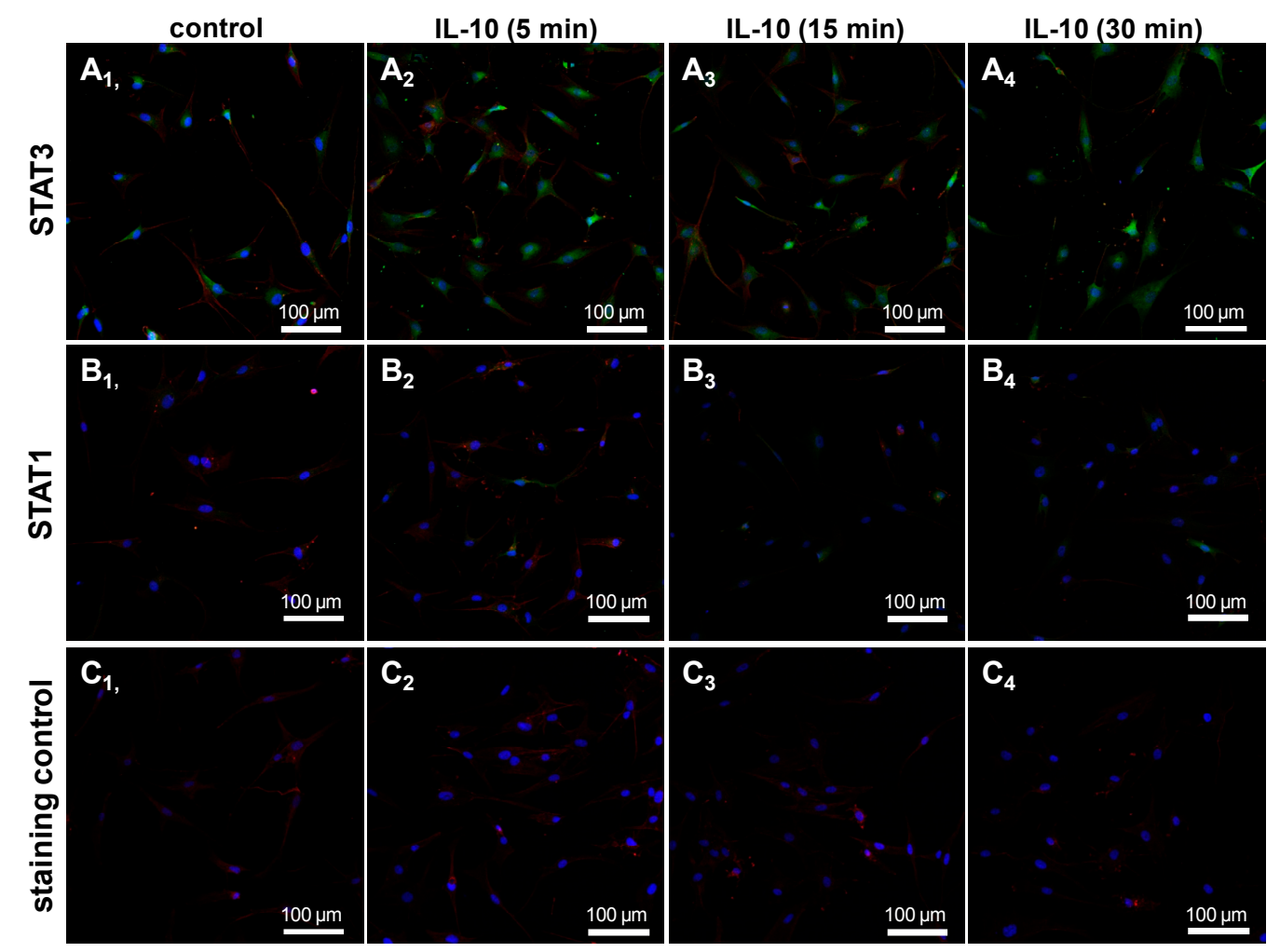

2.4. Gene Expression of Chondrogenic Differentiated MSCs under the Influence of IL-10 and TNFa in High-Density (H-D) Culture

Neither IL-10 nor TNF $\alpha$ inhibited the chondrogenic gene expression during chondrogenic differentiation of MSC. Moreover, in most of the investigated samples, IL-10 had a slightly stimulatory, but not significant effect on the type II collagen, aggrecan and even TNF $\alpha$ expression when compared with the respective undifferentiated and differentiated controls (Figure 6A-D). Despite not reaching the significance level, TNFa had also inductive effects on COL2A1, SOX9, $A C A N$ and $T N F \alpha$ gene expression. The shape and size of the cultures revealed no major differences (Figure 6 $\left.\mathrm{E}_{1}-\mathrm{E}_{7}\right)$. 
Figure 6. Relative gene expression of cartilage markers in H-D cultures after 14 days of differentiation and 7 days cytokine stimulation. The H-D cultures were differentiated for 14 days and stimulated during the last 7 days with either IL-10 or TNF $\alpha$ alone, or in combination (each $10 \mathrm{ng} / \mathrm{mL})$. COL2Al (A, $n=3)$ and $A C A N(\mathbf{B}, n=4)$ encodes main structural components of articular cartilage; $\operatorname{SOX} 9(\mathbf{C}, n=4)$ encodes one of the most important transcription factors during chondrocyte differentiation, whereas $T N F \alpha(\mathbf{D}, n=5)$ encodes a pro-inflammatory cytokine; $\left(\mathbf{E}_{1}-\mathbf{E}_{7}\right)$ Representative macroscopic images of the 14 day old H-D cultures after treatment. Data was normalized. (A-C) The number of experiments did not allow approving a Gaussian distribution of the data. Therefore, a Wilcoxon signed rank test was performed. $p<0.05$; (D) A Gaussian distribution could be determined for the data hence one-sample-t-test, one way ANOVA and Bonferoni post test were used. $n=3-5$ independent experiments with cells of different donors were performed. Co, control; (-) undifferentiated; $(+)$ differentiated.
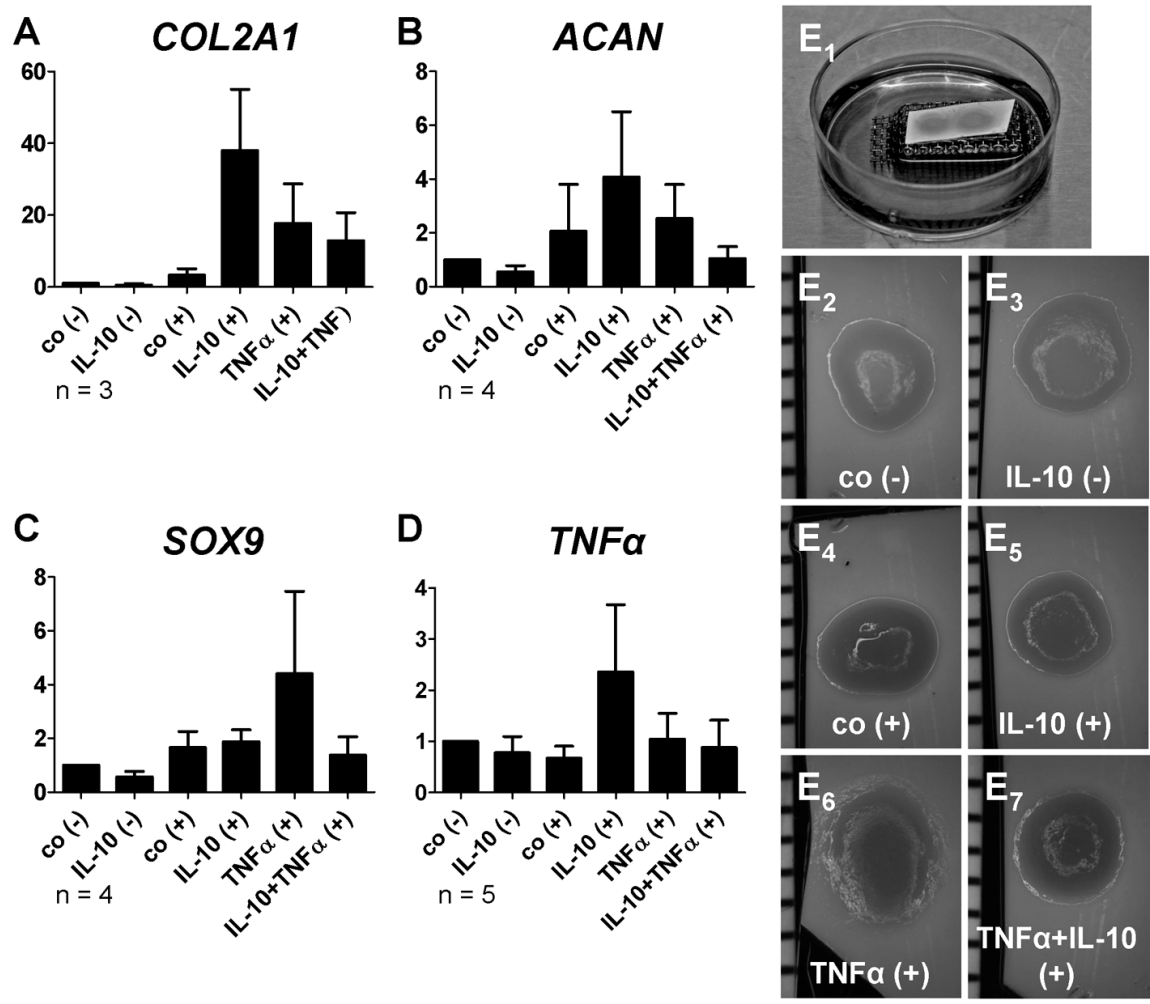

\subsection{Histological Structure and Type II Collagen Expression of MSCs in H-D Culture}

Histological structure of H-D culture under the different treatment conditions was firstly visualized using HE staining (Figure $7 \mathrm{~A}_{1}-\mathrm{A}_{6}$ ). In most cultures the bottom and top cell layers revealed more or less elongated cells whereas the middle of the culture consisted of round cells. Irrespective of cell layer and treatment all cells were embedded into a fibril-rich and alcian blue positive ECM which suggested a substantial content of sulfated glycosaminoglycan (Figure $7 \mathrm{~B}_{1}-\mathrm{B}_{6}$ ). However, cultures treated with TNF $\alpha$ either alone or in combination with IL-10 revealed a looser consistency of the ECM. The ECM of chondrogenically differentiated MSC cultures contained sulfated glycosaminoglycan and type II collagen. There was a slightly higher type II collagen fluorescence intensity in the chondrogenic 3D cultures untreated or treated with IL-10 that correlated with the gene expression results (Figure 7). 
Figure 7. Histology and type II collagen synthesis in chondrogenic differentiated MSCs under the influence of cytokines in H-D cultures. The H-D cultures were differentiated for 14 days and stimulated during the last 7 days with either IL-10 or TNF $\alpha$ alone, or in combination (each $10 \mathrm{ng} / \mathrm{mL})$. HE $\left(\mathbf{A}_{\mathbf{1}}-\mathbf{A}_{6}\right)$ and alcian blue $\left(\mathbf{B}_{1}-\mathbf{B}_{6}\right)$ stainings were performed; Additionally, type II collagen was immunolabelled (green, $\mathbf{C}_{\mathbf{1}}-\mathbf{C}_{\mathbf{6}}$ ). Cell nuclei were counterstained using DAPI (blue). Co, control; $(-)$ undifferentiated; $(+)$ differentiated. Scale bars $=100 \mu \mathrm{m}\left(\mathbf{A}_{\mathbf{1}}-\mathbf{A}_{\mathbf{6}}\right.$ and $\left.\mathbf{B}_{\mathbf{1}}-\mathbf{B}_{\mathbf{6}}\right), 200 \mu \mathrm{m}\left(\mathbf{C}_{\mathbf{1}}-\mathbf{C}_{\mathbf{6}}\right)$.

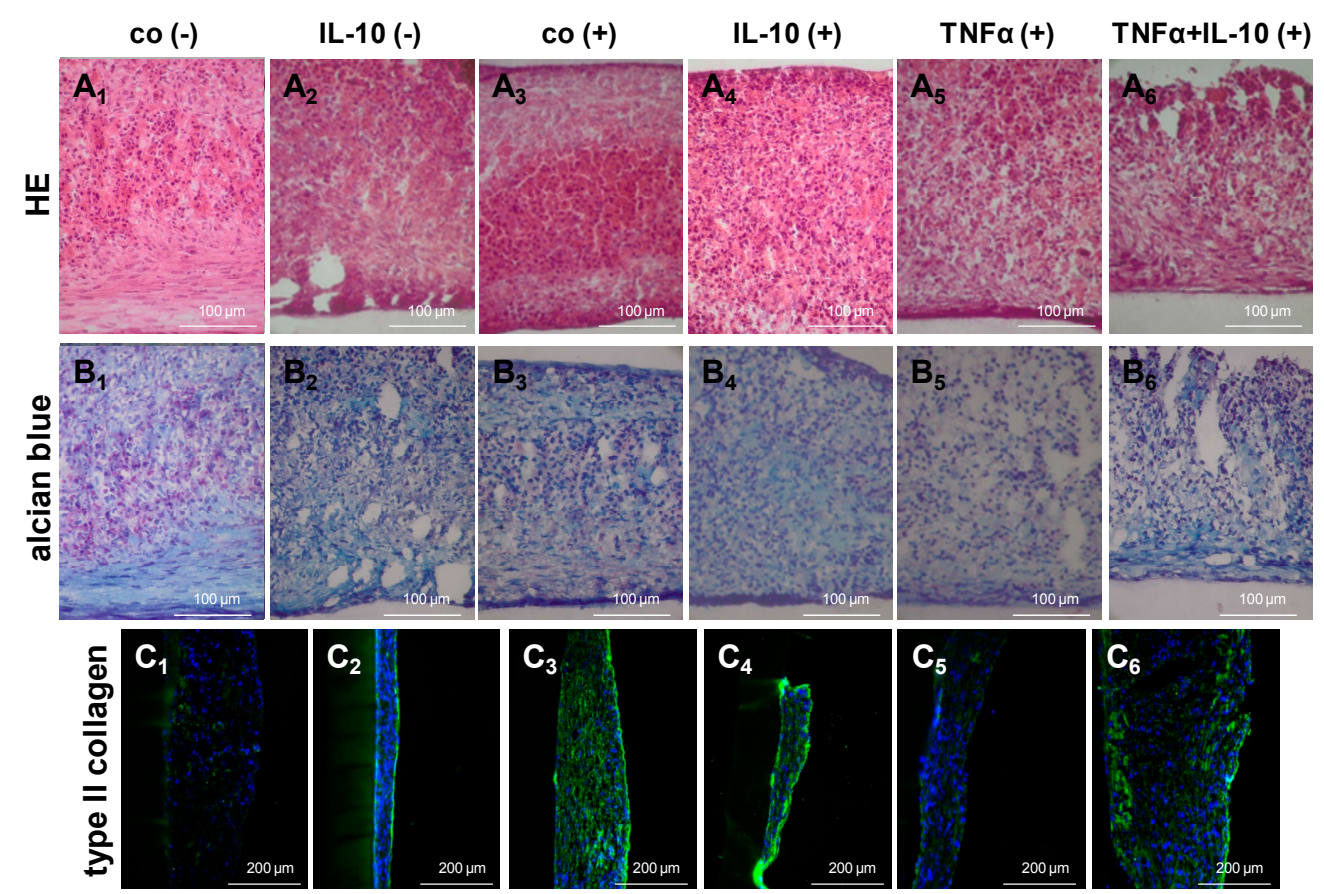

2.6. Chondrogenic Gene Expression and Histology of Chondrogenic Differentiated MSCs in H-D and Polyglycolic Acid (PGA) Culture

To answer the question whether MSCs could undergo chondrogenic differentiation in scaffold culture in a similar manner to the H-D culture, both 3D culture types were directly compared concerning their gene expression profile. Non cultured human articular chondrocytes served as controls. Chondrogenic differentiated MSCs expressed typical cartilage markers, such as type II collagen, aggrecan and sox9 in H-D culture and PGA scaffold culture (Figure 8A-C). However, gene expression of cartilage markers was inferior in chondrogenic differentiated MSCs cultured in both 3D culture systems compared with freshly isolated human articular chondrocytes. Further, despite the difference was not significant, the expression of type II collagen was higher in PGA compared with H-D culture (Figure 8A). The expression level of aggrecan and sox9 revealed no major differences in both culture systems (Figure 8B,C). The PGA seeded for 14-21 days with chondrogenically induced or non induced MSCs were analyzed for cell vitality, histology and protein expression of type II collagen. MSCs adhered on the PGA and formed cell-matrix sails between the PGA fibers (Figure 9A $1, \mathrm{~A}_{2}$ ). The majority of MSCs cultured for 14 days on PGA scaffolds survived irrespectively whether chondrogenically induced or not (Figure 9B1, $\mathrm{B}_{2}$ ).

Not induced and chondrogenically induced chondrocytes cultured in H-D cultures produced an ECM which contained cartilage-specific sulfated glycosaminoglycans (Figure $9 \mathrm{C}_{1}-\mathrm{D}_{2}$ ) and type II 
collagen (Figure 9E1, $\mathrm{E}_{2}$ ). However, the synthesis of cartilage-specific glycosaminoglycans and type II collagen was inferior in undifferentiated cells (Figure 9D1- $\mathrm{E}_{2}$ ).

Figure 8. Relative gene expression of chondrogenic differentiated MSCs in H-D culture and on PGA scaffolds compared with freshly isolated, non-cultured articular chondrocytes (co). MSCs (passage 4-6) underwent chondrogenic differentiation for 14 days. (A) COL2A1; (B) $A C A N$; (C) SOX9. $n=3-4$ independent experiments with cells of different donors were performed. Data was analyzed using the Wilcoxon signed rank test, Kruskal Wallis and Dunns post test.
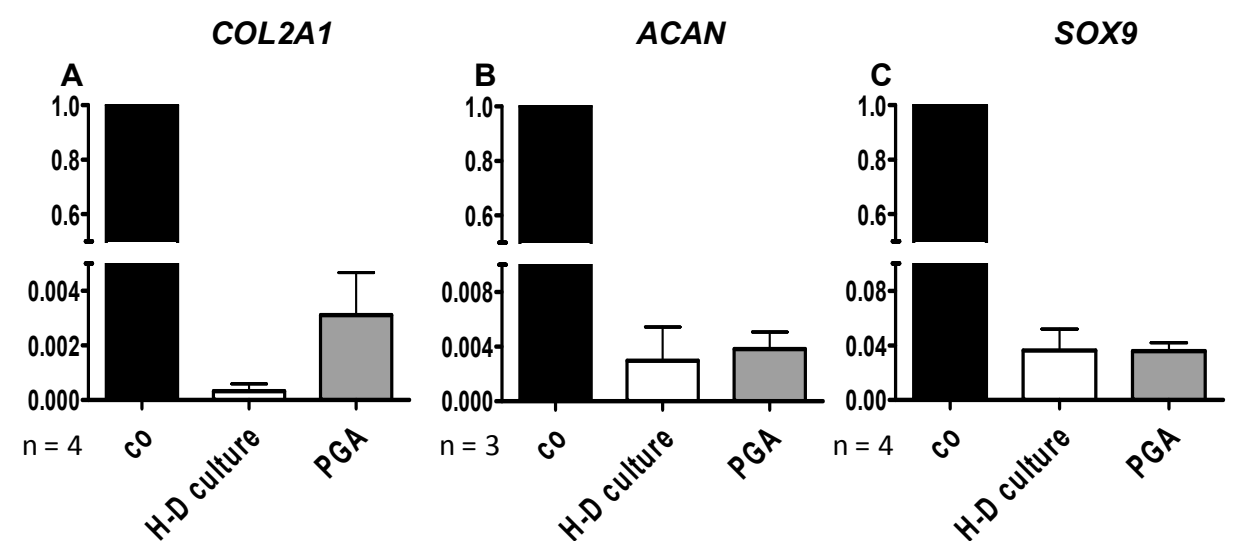

Figure 9. Vitality, histology and type II collagen expression of chondrogenically differentiated and undifferentiated MSCs on PGA scaffolds. Undifferentiated (-) and chondrogenically differentiated $(+)$ MSCs were cultured in PGA. ( $\left.\mathbf{A}_{1}, \mathbf{A}_{2}\right)$ Invert microscopical pictures ("native") of undifferentiated and chondrogenically differentiated MSCs in PGA, $\left(\mathbf{B}_{1}, \mathbf{B}_{2}\right)$ MSCs stained with FDA/PI, dead cells and PGA fibers are red and viable cells are green, $\left(\mathbf{C}_{\mathbf{1}}, \mathbf{C}_{\mathbf{2}}\right) \mathrm{HE},\left(\mathbf{D}_{\mathbf{1}}, \mathbf{D}_{\mathbf{2}}\right)$ alcian blue or immunolabelled for type II collagen $\left(\mathbf{E}_{\mathbf{1}}, \mathbf{E}_{\mathbf{2}}\right)$. In the HE and alcian blue staining the fibers and cell nuclei are stained violet. Cell nuclei were counterstained using DAPI (blue). Scale bars $=200 \mu \mathrm{m}\left(\mathbf{A}_{1}-\mathbf{B}_{2}\right), 100 \mu \mathrm{m}\left(\mathbf{C}_{1}-\mathbf{E}_{2}\right)$.
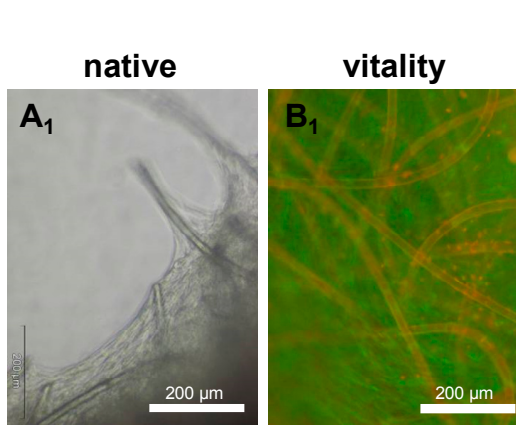

(-) PGA culture
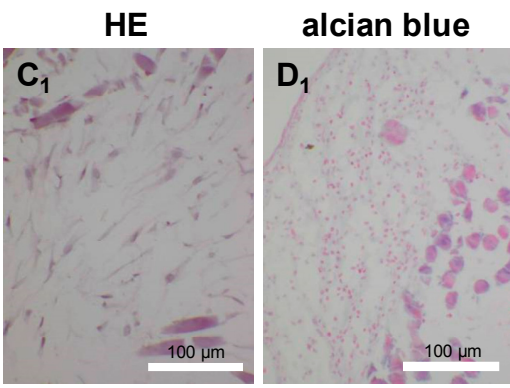

(+) PGA culture
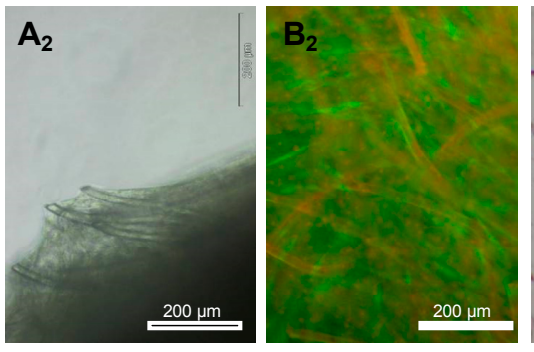
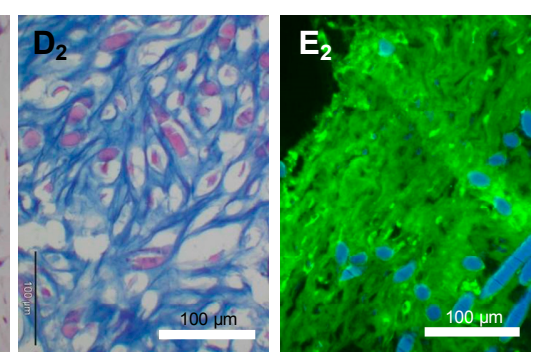


\section{Discussion}

Cartilage defects, degenerative or traumatic, remain one of the major problems in orthopedics, orthopedic surgery and regenerative medicine [26]. Chondrogenically differentiated MSCs could represent a therapeutic option as proposed previously [27]. The aim of this study was to determine the effect of particular anti- and pro-inflammatory cytokines (IL-10, TNF $\alpha$ ) on the chondrogenesis of pre-differentiated MSCs.

In our study, we were able to demonstrate that bone marrow derived MSCs (BM-MSCs) from all donors investigated expressed typical surface molecules for MSCs. The MSC characterization revealed that the isolated, plastic adherent cell population contained nearly no blood cells such as lymphocyte subpopulations and macrophages discernible by CD3-, CD4- and CD8- as well as CD14-negativity. Most of the MSCs were CD29, CD44 and CD90 positive [28,29]. When characterizing MSCs, BM-MSCs were negative for CD34 [28,30,31]. However, the expression of this marker can be influenced by the origin and passage of stem cells, for instance adipose-derived stem cells at early passages may express CD34 [32,33]. This marker is also typical for the hematopoietic stem cells [28]. Accordingly, in the present study, a high rate of cells negative for the hematopoietic marker CD34 became evident. As far as the CD106 is concerned, the expression of this marker differs among the donors and the origin of the MSCs [28,34-36]. The expression of CD106 varied between different donors with the mean of $44.13 \% \pm 28.8 \%$ in our study.

Further MSCs expressed IL-10 and the IL-10R $\alpha$. IL-10 and/or TNF $\alpha$ did not inhibit the chondrogenic differentiation of MSC. The MSCs expressed STAT3 which is the main downstream transcription factor in IL-10 signaling [37]. Some cells of the population revealed an enhanced STAT3 expression and translocation of STAT3 in response to short time IL-10 exposition suggesting their sensibility for IL-10. Sensibility for IL-10 has already been demonstrated by Jung et al. (2013) in MSC micromass cultures [37]. In contrast, STAT1, which can also be induced by IL-10, was only weakly expressed by the MSCs. Furthermore, in most of the investigated samples, IL-10 had a slightly stimulatory effect on the expression of cartilage markers when compared with the respective controls. This observation is in agreement with a study of Jung et al. who demonstrated a role for IL-10 in endochondral bone formation stimulating chondrocyte proliferation and hypertrophic differentiation [37]. These cells were able to differentiate into different cell lineages, indicating the multipotent stem cell character of the isolated cells. After chondrogenic differentiation, MSCs cultured in both H-D and PGA culture systems expressed typical cartilage markers. Every biomaterial implanted in the human body may potentially cause an inflammation or infection followed by a rejection. Therefore, as some authors suggest [18], we investigated also the H-D cultures, a culture system which remains mostly unaffected by the influence of a biomaterial.

We found almost no difference between these two culture systems in the gene expression of $A C A N$ or SOX9. However, the expression of the type II collagen was higher in PGA cultures but the difference did not reach the significance level. It could be assumed that the diffusion in the scaffold culture is easier compared with the H-D culture which is maintained at the medium-air interface and is much denser. The expression profile of cartilage markers was inferior in chondrogenically induced MSCs in both culture systems compared to freshly isolated non cultured chondrocytes underlining the need for further optimization of chondrogenesis. PGA scaffolds have been implicated as a biocompatible 
scaffold for cartilage repair, yet further clinical studies are required [21,38-43]. PGA scaffolds allow chondrogenic differentiation of MSCs not only in vitro but also in vivo. The cartilage defects covered with PGA scaffolds have shown more hyaline-like repair tissue in comparison to different surgical techniques as for instance microfracturing. However, in the in vivo studies so far available only small numbers of animals were investigated and the analyzed cartilage defects were small $[21,22,38,44]$. Therefore, the role of PGA scaffolds in cartilage repair requires further investigation. Unlike pellet cultures, MSCs were cultivated in micromasses on a porous cellulose membrane where the cell conglomerate can easily be isolated for analysis. The limitation of this method for a potential in vivo research is the fact that a great amount of MSCs is required to form a patch big enough to cover cartilage defects. The success of chondrogenic differentiation of MSCs was donor-dependent in this study. Donor and age dependencies of chondrogenic differentiation have already been observed by others $[5,45]$.

In comparison to a healthy tissue, the osteoarthritic joint shows histological features of cartilage degeneration. These features probably support the migration and chondrogenic differentiation of the MSCs [46,47]. Furthermore, traumatic cartilage damage leads to an inflammatory milieu in the joint. High levels of matrix metalloproteinases (MMP) 1 and 3, IL-1 $\beta$ and TNF $\alpha$ have been detected in patients with posttraumatic cartilage defects. These alterations might affect the healing response. TNF $\alpha$ is supposed to play a key role [48-50]. A typical anti-inflammatory cytokine in human chondrocytes is IL-10. It has an anti-apoptotic effect and plays an antagonistic role to TNF $\alpha$ [51]. There exist only spare information about the role and the mechanisms of action of IL-10 in cartilage and under OA conditions. It is supposed to have a protective effect on the cartilage tissue [52]. However, the increase of both, TNF $\alpha$ and IL-10 correlates with the OA progression [53].

The expression of IL-10 has been observed in mesodermal cell types not only in chondrocytes [51] and synovial fibroblasts [54], but also in MSCs of different origins, yet the presence of IL-10R and the effect of this cytokine in BM-MSCs requires further investigation $[23,55,56]$.

Moreover, BM-MSCs are able to induce an IL-10 secretion in other immune cells such as T-cells [57,58]. An important issue is the sensitivity of MSCs for IL-10, which has not been sufficiently addressed so far. The study of Jung et al. indicates that chondrogenic precursor cells are responsive to IL-10 [37]. An inflammatory micromilieu in the joint triggered by pro-inflammatory cytokines which were released by synovium-derived leukocyte subpopulations is known to affect chondrogenesis [59]. It has been reported that $\mathrm{TNF} \alpha$ may enhance the osteogenic differentiation of MSCs in vitro [60-63]. It may also inhibit myogenic differentiation of the myoblasts [64] and the chondrogenic differentiation of chondrocytes [65,66]. In regard to BM-MSCs, the effect of the inflammation, in particular driven by $\mathrm{TNF} \alpha$ has not been thoroughly investigated and certainly has not been fully understood. TNF $\alpha$ is able to induce a joint destruction and it is supposed to block the chondrogenic differentiation of the MSCs via NF- $\kappa B$ activation. Through this pathway transcription of sox9, a crucial transcription factor mediating chondrogenesis, can be blocked [8]. Furthermore, the stimulation of TNF $\alpha$ can inhibit the synthesis of typical cartilage markers such as type II collagen or aggrecan and increase the synthesis of degradative enzymes such as MMPs in the MSCs. Some subtypes of MMPs play a key role during joint cartilage degeneration [67]. Furthermore, TNF $\alpha$ amplifies cytokine expression in MSCs and it is an important regulator of MSC migration [68]. The possibility of TNF $\alpha$ inhibition could be an interesting approach in the therapy of cartilage defects. Interestingly, 
it has been shown recently that intraarticularly administered MSCs are able to impair the systemic $\mathrm{TNF} \alpha$ concentrations underlining their immunomodulatory properties [69]. TNF $\alpha$ inhibitors are already common in the therapy of rheumatoid arthritis $[65,70,71]$.

As shown in the Figure 4, freshly isolated MSC expressed both, IL-10 and its receptor. We could hypothesize that there might exist inductive stimuli modulating IL-10 and IL-10R $\alpha$ expression which were not further investigated by us. IL-10 and/or TNF $\alpha$ did not inhibit the chondrogenic differentiation of MSCs. In contrast, in this study an inductory effect (not significant) of TNF $\alpha$ on the SOX9 gene expression by the MSCs was detected. It might depend on time point of analysis and culture system. Taking in account the important influence of the microenvironment Chung and Burdick reported that the chondrogenesis by MSCs depended on the particular biomaterial used for 3D culturing [27]. However, protein expression levels and the nuclear translocation indicative for activation of sox9 which is mandatory for mediating chondrogenesis was not tested. In most of the investigated samples, IL-10 had a slightly stimulatory effect on the type II collagen and aggrecan expression when compared with the respective controls. Higher expression of TNF $\alpha$ under the influence of IL-10 could implicate an interaction between these particular cytokines in MSCs. Cytokines were applied in a concentration of $10 \mathrm{ng} / \mathrm{mL}$, which is supposed to correlate with the physiological concentration in peripheral blood [72]. Our purpose was to investigate the effect under standard conditions. However, to estimate potentially remedial effect of IL-10 on chondrogenic differentiation of MSCs higher concentrations of the applied cytokines should be considered.

\section{Experimental Section}

\subsection{MSC Isolation}

MSCs were isolated from human femoral head spongiosa (obtained from 10 patients between the age of 55 and 88 undergoing joint replacement surgeries of the hip joints) using density gradient centrifugation with biocoll separating solution (Biochrom AG, Berlin, Germany).

The spongiosa of a femoral head was minced and pressed through a sieve. Bone spongiosa fragments were removed and the liquid rest was pressed through a $140 \mu \mathrm{m}$ pore diameter filter membrane (Millipore, Billerica, MA, USA). To remove the remnants of the particles the isolated cell suspension was washed with phosphate buffered saline (PBS) and centrifuged at $200 \times g$ in $4{ }^{\circ} \mathrm{C}$ for 5 min. The purified pellet was mixed with the biocoll solution (Biochrom AG, Berlin, Germany) and centrifuged at $200 \times \mathrm{g}$ in $4{ }^{\circ} \mathrm{C}$. After $20 \mathrm{~min}$ the interphase containing MSCs was extracted, washed with PBS and centrifuged at $200 \times \mathrm{g}$ in $4{ }^{\circ} \mathrm{C}$ for $5 \mathrm{~min}$. Subsequently, MSCs were resuspended in stem cell growth medium (Table 1) and seeded in culture flasks for cell expansion (Cell plus culture flask, Sarstedt, Nümbrecht, Germany). The cultivation proceeded at $37{ }^{\circ} \mathrm{C}, 90 \%$ air humidity and $5 \% \mathrm{CO}_{2}$. The growth medium was changed every 2-3 days. 
Table 1. Chemical composition of used growth media.

\begin{tabular}{|c|c|}
\hline Stem Cell Growth Medium & Concentration \\
\hline Selenium (Sigma-Aldrich, Munich, Germany) & $5 \mathrm{ng} / \mathrm{mL}$ \\
\hline Transferrin (Sigma-Aldrich) & $5 \mu \mathrm{g} / \mathrm{mL}$ \\
\hline Linoleic acid (Sigma-Aldrich) & $4.7 \mu \mathrm{g} / \mathrm{mL}$ \\
\hline Insulin (Sigma-Aldrich) & $5 \mu \mathrm{g} / \mathrm{mL}$ \\
\hline Ascorbic acid (Sigma-Aldrich) & $1 \mu \mathrm{g} / \mathrm{mL}$ \\
\hline Dexamethasone (Sigma-Aldrich) & $1 \mu \mathrm{g} / \mathrm{mL}$ \\
\hline MCDB 201 with L-glutamine solution (Sigma-Aldrich) & $34 \mathrm{~mL} / 100 \mathrm{~mL}$ \\
\hline Dulbecco's modified Eagle's medium (Biochrom AG) & $51 \mathrm{~mL} / 100 \mathrm{~mL}$ \\
\hline Fetal calf serum (FCS, Biochrom AG) & $15 \mathrm{~mL} / 100 \mathrm{~mL}$ \\
\hline Streptomycin (Biochrom AG) & $50 \mathrm{IU} / \mathrm{mL}$ \\
\hline Penicillin (Biochrom AG) & $50 \mathrm{IU} / \mathrm{mL}$ \\
\hline Chondrocytes Growth Medium & Concentration \\
\hline $\begin{array}{l}\text { Ham's F-12/Dulbecco's modified Eagle's medium supplemented with } 25 \mu \mathrm{g} / \mathrm{mL} \text { ascorbic acid } \\
\text { (Sigma-Aldrich) }\end{array}$ & $1000 \mathrm{~mL}$ \\
\hline Streptomycin (Biochrom AG) & $50 \mathrm{IU} / \mathrm{mL}$ \\
\hline Penicillin (Biochrom AG) & $50 \mathrm{IU} / \mathrm{mL}$ \\
\hline Amphotericin B (Biochrom AG) & $2.5 \mu \mathrm{g} / \mathrm{mL}$ \\
\hline Essential amino acids (Biochrom AG) & $1 \mathrm{~mL} / 100 \mathrm{~mL}$ \\
\hline Fetal calf serum (Biochrom AG) & $1 \mathrm{~mL} / 100 \mathrm{~mL}$ \\
\hline Lipogenic Medium & Concentration \\
\hline Indomethacin (Sigma-Aldrich) & $2 \mu \mathrm{L} / \mathrm{mL}$ \\
\hline Isobutyl-1-methylxanthine (Sigma-Aldrich) & $1 \mu \mathrm{L} / \mathrm{mL}$ \\
\hline Rosiglitazone (Sigma-Aldrich) & $1 \mu \mathrm{L} / \mathrm{mL}$ \\
\hline Insulin (Sigma-Aldrich) & $4 \mu \mathrm{L} / \mathrm{mL}$ \\
\hline Dexamethasone (Sigma-Aldrich) & $1 \mu \mathrm{L} / \mathrm{mL}$ \\
\hline Fetal calf serum (FCS, Biochrom AG) & $0.1 \mathrm{~mL} / \mathrm{mL}$ \\
\hline Streptomycin (Biochrom AG) & $50 \mathrm{IU} / \mathrm{mL}$ \\
\hline Penicillin (Biochrom AG) & $50 \mathrm{IU} / \mathrm{mL}$ \\
\hline HEPES (Biochrom AG) & $25 \mu \mathrm{L} / \mathrm{mL}$ \\
\hline Dulbecco's modified Eagle's medium with $3.7 \mathrm{~g} / \mathrm{L} \mathrm{NaHCO}_{3}$ and $4.5 \mathrm{~g} / \mathrm{L}$ glucose (Biochrom AG) & $10 \mathrm{~mL}$ \\
\hline Osteogenic Medium & Concentration \\
\hline Dexamethasone (Sigma-Aldrich) & $1 \mu \mathrm{L} / \mathrm{mL}$ \\
\hline Glycerol-3-phosphate (Sigma-Aldrich) & $10 \mu \mathrm{L} / \mathrm{mL}$ \\
\hline Ascorbic acid (Sigma-Aldrich) & $2 \mu \mathrm{L} / \mathrm{mL}$ \\
\hline HEPES (Biochrom AG) & $25 \mu \mathrm{L} / \mathrm{mL}$ \\
\hline Streptomycin (Biochrom AG) & $50 \mathrm{IU} / \mathrm{mL}$ \\
\hline Penicillin (Biochrom AG) & $50 \mathrm{IU} / \mathrm{mL}$ \\
\hline Chondrogenic Medium & Concentration \\
\hline L-Glutamine (Biochrom AG) & $10 \mu \mathrm{L} / \mathrm{mL}$ \\
\hline HEPES (Biochrom AG) & $25 \mu \mathrm{L} / \mathrm{mL}$ \\
\hline Sodium pyruvate (Sigma-Aldrich) & $10 \mu \mathrm{L} / \mathrm{mL}$ \\
\hline Dexamethason (Sigma-Aldrich) & $0.1 \mu \mathrm{L} / \mathrm{mL}$ \\
\hline Ascorbic acid (Sigma-Aldrich) & $1.7 \mu \mathrm{L} / \mathrm{mL}$ \\
\hline Prolin (Sigma-Aldrich) & $1 \mu \mathrm{L} / \mathrm{mL}$ \\
\hline ITS+1 (Sigma-Aldrich) & $10 \mu \mathrm{L} / \mathrm{mL}$ \\
\hline Streptomycin (Biochrom AG) & $50 \mathrm{IU} / \mathrm{mL}$ \\
\hline Penicillin (Biochrom AG) & $50 \mathrm{IU} / \mathrm{mL}$ \\
\hline TGF- $\beta 1$ (Pepro Tech GmbH, Hamburg, Germany) & $10 \mathrm{ng} / \mathrm{mL}$ \\
\hline Dulbecco's modified Eagle's medium with $3.7 \mathrm{~g} / \mathrm{L} \mathrm{NaHCO}_{3}$ and $4.5 \mathrm{~g} / \mathrm{L}$ glucose (Biochrom AG) & $10 \mathrm{~mL}$ \\
\hline
\end{tabular}




\subsection{Chondrocyte Isolation}

Freshly isolated non cultured human articular chondrocytes served as a positive control. Primary human articular chondrocytes and MSCs were isolated in accordance with the institutional ethical committee of the Charité-University Medical School Berlin, Campus Benjamin Franklin (Berlin, Germany; Register ID: EA4 024 09; 27 July 2009). Human femoral head articular cartilage chips were obtained from 3 female patients between the age of 83 and 90 undergoing joint replacement surgery for femoral neck fractures. Each surgery was performed within $24 \mathrm{~h}$ after the trauma. Chips were cut into small slices followed by digestion with pronase deriving from Streptomyces griseus at $20 \mathrm{mg} / \mathrm{mL}$ (7 U/mg, Roche Diagnostics, Mannheim, Germany) in Ham's F-12/Dulbecco's modified Eagle's medium (50/50, Biochrom-AG, Berlin, Germany) for $30 \mathrm{~min}$ at $37^{\circ} \mathrm{C}$ and subsequently with collagenase NB5 deriving from Clostridium histolyticum at $1 \mathrm{mg} / \mathrm{mL}$ (Serva, Heidelberg, Germany) in chondrocyte growth medium (Table 1). Isolated chondrocytes were resuspended in chondrocyte growth medium containing 10\% FCS and seeded in culture flasks (Cell plus culture flask).

\subsection{MSC Characterisation Using Flow Cytometry}

Subsequently to the isolation, approximately $3 \times 10^{6}$ MSCs from each donor were rinsed in PBS followed by a fixation with 4\% paraformaldehyde (PFA) solution (Santa Cruz Biotechnology, Inc., Santa Cruz, CA, USA) for $15 \mathrm{~min}$. To characterize the cell type, fixed MSCs were washed with PBS, centrifuged at $400 \times g$ and labelled with the following mouse anti-human antibodies: CD3, CD4, CD8, CD14, CD29, CD34, CD44, CD90 and CD106. The solution with primary labelled antibodies was diluted 1:200 in PBS and the solution with unlabelled antibodies 1:20 in PBS. Fifty micro liters of each diluted antibody solution was added to approximately $2 \times 10^{5} \mathrm{MSCs}$. The incubation lasted for $30 \mathrm{~min}$ at room temperature (RT). Afterwards, the MSCs were washed in PBS and centrifuged at $400 \times g$. The supernatants were decanted and the probes were suspended in FACS-buffer consisting of $1 \times$ PBS, $1 \%$ bovine serum albumin (BSA, Carl Roth $\mathrm{GmbH}$, Karlsruhe, Germany) and 0.01\% sodium acid. The unlabeled primary antibodies were detected with appropriate secondary immunophor-labelled secondary antibody solution, diluted 1:200 in PBS, for $30 \mathrm{~min}$ at RT. All probes were washed in PBS and centrifuged at $400 \times g$. The supernatants were decanted and the probes were suspended in FACS-buffer for analysis. All specifications of used antibodies are listed in (Table 2).

All samples were measured using FACS calibur flow cytometer (BD Bioscience, San Jose, CA, USA). For the analysis of the results FlowJo 7.0 (Tree Star Inc., Ashland, OR, USA) was used.

\subsection{Chondrogenic, Adipogenic and Osteogenic Differentiation of MSCs}

Four H-D cultures from each donor underwent a chondrogenic differentiation that took 14 days. To confirm the multipotency of the MSCs, additionally a chondrogenic, adipogenic and osteogenic differentiation was performed in monolayer culture.

Subsequently to the cultivation process, $20 \mu \mathrm{M}$ azacytidine (Sigma-Aldrich, Munich, Germany) was added to the growth medium for $24 \mathrm{~h}$. After $24 \mathrm{~h}$ approximately $6 \times 10^{4}$ MSCs were cultured as monolayer on cover slips in one well of a 6 well plate. Each well was incubated with $2 \mathrm{~mL}$ adipogenic or osteogenic medium (Table 1). The adipogenic medium was changed every two days and after five 
days the MSC growth medium was added for two days. Two thirds of the osteogenic medium was changed every two or three days. The cover slips with differentiating MSCs were analyzed after 14, 21 and 28 days. To determine the osteogenic differentiation we used von Kossa staining and for the adipogenic differentiation oil red staining (Figure 3).

Table 2. Antibodies to surface markers used for flow cytometry and immunofluorescence labeling.

\begin{tabular}{|c|c|}
\hline Primary Antibody & Secondary Antibody \\
\hline $\begin{array}{l}\text { CD3, mouse anti-human CD3 (mouse IgG2a), } r \text {-phycoerythrin } \\
\text { conjugate (Caltag, Buckingham, UK) }\end{array}$ & none \\
\hline $\begin{array}{l}\text { CD4, mouse anti-human CD } 4 \text { (mouse IgG2a), fluorescein } \\
\text { (FITC) conjugate (Caltag) }\end{array}$ & none \\
\hline $\begin{array}{l}\text { CD8, mouse anti-human CD } 8 \text { (mouse IgG2a), fluorescein } \\
\text { (FITC) conjugate (Caltag) }\end{array}$ & none \\
\hline $\begin{array}{l}\text { CD14, mouse anti-human CD14 antigen (mouse IgG 2a), } \\
\text { fluorescein (FITC) conjugate (Invitrogen, Carlsbad, } \\
\text { CA, USA) }\end{array}$ & none \\
\hline $\begin{array}{l}\text { CD29, mouse anti-human Integrin } \beta 1 \text { monoclonal antibody } \\
\text { (mouse IgG1) (Millipore, Billerica, MA, USA) }\end{array}$ & $\begin{array}{l}\text { Donkey F(ab)2 Fragment-anti-mouse-APC } \\
\text { (Dianova, Hamburg, Germany) }\end{array}$ \\
\hline $\begin{array}{l}\text { CD34, mouse anti-human CD34 (mouse IgG1, k), } \\
\text { allophycocyanin (APC) conjugate } \\
\text { (BD Pharmingen, Franklin Lakes, NJ, USA) }\end{array}$ & none \\
\hline $\begin{array}{l}\text { CD44, mouse anti-human CD } 44 \text { antibody (mouse IgG 2a) } \\
\text { (Cell signaling, Cambridge, UK) }\end{array}$ & $\begin{array}{l}\text { Donkey F(ab)2 Fragment-anti-mouse-APC } \\
\text { (Dianova, Hamburg, Germany) }\end{array}$ \\
\hline $\begin{array}{l}\text { CD90, mouse anti-human CD90 (mouse IgG1, k), fluorescein } \\
\text { (FITC) conjugate (BD Pharmingen) }\end{array}$ & none \\
\hline $\begin{array}{l}\text { CD106, mouse anti-human VCAM-1 monoclonal antibody } \\
\text { (mouse IgG1) (Chemicon, Billerica, MA, USA) }\end{array}$ & $\begin{array}{l}\text { Donkey F(ab)2 Fragment-anti-mouse-APC } \\
\text { (Dianova) }\end{array}$ \\
\hline $\begin{array}{l}\text { Type II collagen, rabbit anti-human polyclonal antibody } \\
\text { (Acris Antibodies, Herford, Germany) }\end{array}$ & $\begin{array}{l}\text { Alexa-Fluor }{ }^{\circledR} 488, \text { donkey-anti-rabbit } \\
\text { (Invitrogen) }\end{array}$ \\
\hline $\begin{array}{l}\text { IL-10, rabbit anti-human polyclonal antibody } \\
\text { (tebu bio GmbH, Le-Perray-en-Yvelines, France) }\end{array}$ & $\begin{array}{l}\text { Alexa-Fluor }{ }^{\circledR} 488, \text { donkey-anti-rabbit } \\
\text { (Invitrogen) }\end{array}$ \\
\hline $\begin{array}{l}\text { IL-10-Receptor- } \alpha \text {, mouse anti-human monoclonal antibody } \\
\text { (Sigma-Aldrich) }\end{array}$ & $\begin{array}{l}\text { Alexa-Fluor }{ }^{\circledR} 488, \text { donkey-anti-mouse } \\
\text { (Invitrogen) }\end{array}$ \\
\hline $\begin{array}{l}\text { STAT1, rabbit anti-human monoclonal antibody } \\
\text { (Cell Signaling) }\end{array}$ & $\begin{array}{l}\text { Alexa-Fluor }{ }^{\circledR} 488, \text { donkey-anti-mouse } \\
\text { (Invitrogen) }\end{array}$ \\
\hline $\begin{array}{l}\text { STAT3, rabbit anti-human monoclonal antibody } \\
\text { (Cell Signaling) }\end{array}$ & $\begin{array}{l}\text { Alexa-Fluor }{ }^{\circledR} 488 \text {, donkey-anti-mouse } \\
\text { (Invitrogen) }\end{array}$ \\
\hline
\end{tabular}

\subsection{MSCs in H-D Culture and Cultured in Non-Woven PGA Scaffolds}

One million eight hundred thousand MSCs, expanded at least until passage 4-6 to achieve sufficient cell numbers, were introduced in scaffold-free H-D culture.

For each donor, one 6-well-plate was prepared for six scaffold-free H-D cultures. In each well one metal grid was placed and covered with a cellulose acetate filter (pore size $0.2 \mu \mathrm{m}$, Sartorius AG, Göttingen, Germany) on the top of it. MSCs were detached from culture flasks using $0.05 \%$ 
trypsin/0.02\% EDTA (Biochrom AG), washed with PBS and centrifuged in falcon tubes twice. Eight to ten micro liters of the pure MSC cell pellet was transferred on each of the filter membrane. To avoid direct contact between growth medium and the 3D culture, only $1.8 \mathrm{~mL}$ of medium per well was added. The cultivation proceeded at $37{ }^{\circ} \mathrm{C}, 90 \%$ air humidity and $5 \% \mathrm{CO}_{2}$. Additionally, about $4 \times 10^{6}$ MSCs per donor were transferred to non-woven PGA scaffolds $(1 \times 1 \times 0.11 \mathrm{~cm})$ which were cultured in the insert of a two chamber system (pore size $0.4 \mu \mathrm{m}$, Beckton-Dickinson, Franklin Lakes, NJ, USA). The scaffolds remained in alginate coated 6-well plates with $3 \mathrm{~mL}$ of chondrogenic induction or stem cell growth medium (control) per well. The cultivation under chondrogenic or non-chondrogenic conditions proceeded at $37{ }^{\circ} \mathrm{C}, 90 \%$ air humidity and $5 \% \mathrm{CO}_{2}$. The 14-day-old scaffolds were rinsed in PBS and then incubated in fluorescein diacetate (FDA) ( $3 \mu \mathrm{g} / \mathrm{mL}$ dissolved in acetone (stock solution), Sigma-Aldrich and further diluted 1:1000 in PBS (working solution)) for $15 \mathrm{~min}$ at $37{ }^{\circ} \mathrm{C}$, rinsed three times with PBS before being counterstained with propidium iodide (PI, Sigma-Aldrich) solution (1 mg/mL dissolved in PBS (stock solution), Sigma-Aldrich, further diluted 1:100 in PBS (working solution)) for $1 \mathrm{~min}$ in the dark at RT. The green or red fluorescence was visualized using fluorescence microscopy.

\subsection{Differentiation of MSCs and Stimulation with Cytokines}

Four H-D cultures were chondrogenic differentiated for seven days in chondroinductive medium (Table 1). Two additional H-D cultures remained undifferentiated and were treated only with MSC growth medium.

For the next 7 days the chondrogenic differentiated H-D cultures were stimulated with $10 \mathrm{ng} / \mathrm{mL}$ recombinant IL-10, TNF $\alpha$ (both: Peprotech GmbH, Hamburg, Germany), TNF $\alpha$ with IL-10, or remained untreated. One undifferentiated $\mathrm{H}-\mathrm{D}$ culture was stimulated with $10 \mathrm{ng} / \mathrm{mL}$ recombinant IL-10 and one culture remained untreated.

\subsection{Histological Staining Procedures}

For histological staining procedures cryo-sections (thickness: $7 \mu \mathrm{m}$ ), or cover slips were used. For Haematoxylin \& Eosin (HE) staining sections were incubated for 4 min in Harris haematoxylin solution (Sigma-Aldrich) rinsed in water and counterstained for 4 min in eosin (Carl Roth $\mathrm{GmbH}$, Karlsruhe, Germany).

For alcian blue $(\mathrm{AB})$ staining, the sections or cover slips were incubated for $3 \mathrm{~min}$ in $1 \%$ acetic acid and then stained $30 \mathrm{~min}$ in $1 \% \mathrm{AB}(\mathrm{Carl}$ Roth $\mathrm{GmbH})$. Subsequently, they were rinsed in 3\% acetic acid. Counterstaining of cell nuclei was performed using nuclear fast red aluminum sulfate solution (Carl Roth $\mathrm{GmbH}$ ) for $5 \mathrm{~min}$.

For von Kossa staining, the sections, or the cover slips were incubated for 5 min in methanol, rinsed in water and then stained $30 \mathrm{~min}$ in $1 \%$ silver nitrate. After rinsing in water, a reduction with $5 \%$ sodium bicarbonate was performed for $7 \mathrm{~min}$. Counterstaining of cell nuclei was performed using nuclear fast red aluminum sulfate solution (Carl Roth $\mathrm{GmbH}$ ) for $5 \mathrm{~min}$.

For oil red staining, the cover slips were incubated for $20 \mathrm{~min}$ in $4 \%$ PFA, rinsed in PBS and then stained $30 \mathrm{~min}$ in $60 \%$ oil red solution (Sigma-Aldrich). 
Finally, all sections were rinsed with aqua dest, and subsequently dehydrated in an ascending alcohol series. Then, the sections were embedded with Entellan (Merck, Darmstadt, Germany). All slices were analyzed by light microscopy (Axioskop 40 microscope: Zeiss Jena, Jena, Germany). Imaging of the sections were achieved using an Olympus digital camera XC30 (Olympus Soft Imaging Solutions GmbH, Muenster, Germany).

\subsection{Gene Expression Analysis Using RTD-PCR}

Gene expression was determined using RTD-PCR. MSCs were cultured for at least 14 days in 3D culture. MSC total RNA was isolated using MasterPure ${ }^{\mathrm{TM}}$ Plant RNA Purification Kit (MasterPure Plant, RNA Purification-Kit, Epicentre, Biotechnologies, Madison, WI, USA). RNA quantity and quality was evaluated with the RNA 6000 Nano assay (Agilent Technologies, Santa Clara, CA, USA). Equal amounts of total RNA (500 ng in a volume of $20 \mu \mathrm{L}$ ) were reverse transcribed using the Qiagen QuantiTect reverse transcription Kit (Qiagen, Hilden, Germany) according to the manufacturer's instructions. One micro liter aliquots containing $16.7 \mathrm{ng}$ of cDNA were amplified by RTD-PCR in a $20-\mu \mathrm{L}$ reaction mixture using specific primer pairs for COL2A1, ACAN, SOX9, TNF $\alpha$ and the house-keeping gene $A C T B$ (all: Applied Biosystems, Foster City, CA, USA). Assays were performed using the TaqMan Gene Expression Assay (Applied Biosystems) or the Quantitec Gene Expression Assay (Qiagen) in an Opticon 1 Real-Time-Cycler (Opticon ${ }^{\mathrm{TM}}$ RTD-PCR, Bio-Rad, Hercules, CA, USA) according to the manufacturer's protocols. We performed for each primer (Table 3) used in this study an efficiency testing using a linear regression analysis using MSC cDNA. Relative amounts of mRNA expression for the gene of interest, and the $A C T B$ were calculated using the $\Delta \Delta C_{\mathrm{t}}$ method [73].

Table 3. Sequences of the primers used in the present study.

\begin{tabular}{|c|c|c|c|}
\hline Gene (Symbol) & NCBI Gene Reference & Length & Manufacturer \\
\hline$\beta$-actin $(A C T B)$ & NM_001101.2 & 171 & $\mathrm{ABI}^{\circledR} *$ \\
\hline aggrecan $(A C A N)$ & NM_013227.2 & 93 & $\mathrm{ABI}^{\circledR} *$ \\
\hline $\operatorname{sox} 9(\operatorname{SOX} 9)$ & NM_000346.2 & 102 & $\mathrm{ABI}^{\circledR} *$ \\
\hline$T N F \alpha(T N F \alpha)$ & NM_000594.2 & 80 & $\mathrm{ABI}^{\circledR} *$ \\
\hline$\beta$-actin $(A C T B)\left(5^{\prime}-3^{\prime}\right)$ & $\begin{array}{c}\text { TGGGACGACATGGAGAA/ } \\
\text { GAAGGTCTCAAACATGATCTGG }\end{array}$ & 146 & Qiagen $^{\circledR}$ \\
\hline type II collagen (COL2A1) & NM_001844, NM_033150 & 142 & Qiagen $^{\circledR}$ \\
\hline
\end{tabular}

* ABI, Applied Biosystems ${ }^{\circledR}$ (Life Technologies ${ }^{\mathrm{TM}}$, Carlsbad, CA, USA).

\subsection{Immunolabelling}

Undifferentiated MSCs isolated from three different donors were cultured for $48 \mathrm{~h}$ on cover slides. Cryo-sections of 14-day-old 3D cultures and cover slides with cells were fixed with 4\% PFA solution for $15 \mathrm{~min}$ before rinsed in Tris buffered saline (TBS: $0.05 \mathrm{M}$ Tris, $0.015 \mathrm{M} \mathrm{NaCl}, \mathrm{pH}$ 7.6). Sections were subsequently blocked with protease-free donkey serum ((Merck Millipore), 5\% diluted in TBS) for $30 \mathrm{~min}$ at RT, rinsed and incubated with the anti-type II collagen antibody in a humidifier chamber overnight at $4{ }^{\circ} \mathrm{C}$. Cover slides were immunolabelled with anti-IL-10, IL-10R $\alpha$, STAT1, STAT3, CD3, CD4, CD8, CD14, CD29, CD34, CD44, CD90, CD106 antibodies. Sections and cover slides were subsequently washed with TBS before incubation with Alexa-Fluor ${ }^{\circledR} 488$ secondary antibodies for 
30 min at RT. STAT3 and STAT1 immunolabelling was combined with phalloidin-CruzFluor555-staining (diluted 1:200 in blocking buffer, Santa Cruz Biotechnology, Biotechnology, Santa Cruz, CA, USA) to depict the cytoskeleton. Negative controls included omitting the primary antibody or using human $\mathrm{IgG}$ as primary antibody during the staining procedure. Cell nuclei were counterstained using 4',6-diamidino-2-phenylindole (DAPI) $(0.1 \mu \mathrm{g} / \mathrm{mL}$, Roche Diagnostics, Mannheim, Germany). Labelled sections were rinsed several times with TBS, embedded with Fluoromount G (Southern Biotech, Biozol Diagnostica, Birmingham, AL, USA) and examined using fluorescence microscopy (Axioskop 40) or confocal laser scanning microscopy (SPE-II, Leica, Wetzlar, Germany). Images were taken using the XC30 camera. All specifications of used antibodies are listed in (Table 2).

\subsection{Statistical Analysis}

All values were expressed as mean with standard deviation. Kolmogorov-Smirnov test was used to detect the presence of Gaussian distribution. Data of experiments where the Gaussian distribution could not be determined due to only $n=3-4$ was analyzed using the Wilcoxon signed rank test, Kruskal Wallis and Dunns post test (GraphPad Prism 5, GraphPad Software Inc., San Diego, CA, USA). Data for which a Gaussian distribution could be proven were analyzed using one-sample- $t$-test, one way ANOVA and Bonferoni post test. Statistical significance was set at a $p$ value of $\leq 0.05$.

\section{Conclusions}

In summary, independent of the 3D culture system used for differentiation, the expression of chondrogenic markers was lower in differentiated MSCs compared with freshly isolated chondrocytes. Chondrogenic differentiated MSCs expressed COL2A1, ACAN and SOX9. An improved understanding of IL-10 and TNF $\alpha$ involvement in chondrogenesis could be a key issue to optimize cell-based joint repair strategies, so the influence of IL-10 and TNF $\alpha$ on MSC differentiation requires further investigation.

\section{Acknowledgments}

This study was supported by equipment founded by the Sonnenfeld foundation, Berlin, Germany, for which we want to express our gratitude at this point. We thank Benjamin Kohl, Tobias Schneider and Nicole Wächter for their support.

\section{Author Contributions}

Michal Jagielski (M.J.) performed most of the experiments and analyzed the majority of data. Johannes Wolf (J.W.) performed the PGA culture experiments. Ulrike Marzahn (U.M.) was involved in several experiments such as RTD-PCR. Anna Völker (A.V.) developed the methods and protocols in the start phase of the project. Marion Lemke (M.L.) isolated the MSCs and was involved in cell culture procedures and stainings. Carola Meier (C.M.) performed the histological experiments. Wolfgang Ertel (W.E.) and Owen Godkin (O.G.) (native English speaker) proof read, corrected added parts of the manuscript. Stephan Arens (S.A.) collected the samples and corrected the manuscript. M.J. and Gundula Schulze-Tanzil (G.S.-T.) developed the experimental design and wrote the main body of the manuscript. 


\section{Conflicts of Interest}

The authors declare no conflict of interest.

\section{References}

1. Filardo, G.; Vannini, F.; Marcacci, M.; Andriolo, L.; Ferruzzi, A.; Giannini, S.; Kon, E. Matrix-assisted autologous chondrocyte transplantation for cartilage regeneration in osteoarthritic knees: Results and failures at midterm follow-up. Am. J. Sports Med. 2013, 41, 95-100.

2. Kon, E.; Filardo, G.; di Matteo, B.; Perdisa, F.; Marcacci, M. Matrix assisted autologous chondrocyte transplantation for cartilage treatment: A systematic review. Bone Jt. Res. 2013, 2, $18-25$.

3. Steinwachs, M.R.; Guggi, T.; Kreuz, P.C. Marrow stimulation techniques. Injury 2008, 39, S26-S31.

4. Pelttari, K.; Steck, E.; Richter, W. The use of mesenchymal stem cells for chondrogenesis. Injury 2008, 39, S58-S65.

5. Yoo, J.U.; Barthel, T.S.; Nishimura, K.; Solchaga, L.; Caplan, A.I.; Goldberg, V.M.; Johnstone, B. The chondrogenic potential of human bone-marrow-derived mesenchymal progenitor cells. J. Bone Jt. Surg. Am. 1998, 80, 1745-1757.

6. Goldring, M.B.; Otero, M.; Plumb, D.A.; Dragomir, C.; Favero, M.; el Hachem, K.; Hashimoto, K.; Roach, H.I.; Olivotto, E.; Borzi, R.M.; et al. Roles of inflammatory and anabolic cytokines in cartilage metabolism: Signals and multiple effectors converge upon MMP-13 regulation in osteoarthritis. Eur. Cells Mater. 2011, 21, 202-220.

7. Fernandes, J.C.; Martel-Pelletier, J.; Pelletier, J.P. The role of cytokines in osteoarthritis pathophysiology. Biorheology 2002, 39, 237-246.

8. Wehling, N.; Palmer, G.D.; Pilapil, C.; Liu, F.; Wells, J.W.; Muller, P.E.; Evans, C.H.; Porter, R.M. Interleukin-1 $\beta$ and tumor necrosis factor $\alpha$ inhibit chondrogenesis by human mesenchymal stem cells through NF-кB-dependent pathways. Arthritis Rheumatol. 2009, 60, 801-812.

9. Bocker, W.; Docheva, D.; Prall, W.C.; Egea, V.; Pappou, E.; Rossmann, O.; Popov, C.; Mutschler, W.; Ries, C.; Schieker, M. IKK-2 is required for TNF- $\alpha$-induced invasion and proliferation of human mesenchymal stem cells. J. Mol. Med. 2008, 86, 1183-1192.

10. Chen, F.H.; Tuan, R.S. Mesenchymal stem cells in arthritic diseases. Arthritis Res. Ther. 2008, 10, doi:10.1186/ar2514.

11. Jui, H.Y.; Lin, C.H.; Hsu, W.T.; Liu, Y.R.; Hsu, R.B.; Chiang, B.L.; Tseng, W.Y.; Chen, M.F.; $\mathrm{Wu}$, K.K.; Lee, C.M. Autologous mesenchymal stem cells prevent transplant arteriosclerosis by enhancing local expression of interleukin-10, interferon- $\gamma$, and indoleamine 2,3-dioxygenase. Cell Transplant. 2012, 21, 971-984.

12. Kang, J.W.; Koo, H.C.; Hwang, S.Y.; Kang, S.K.; Ra, J.C.; Lee, M.H.; Park, Y.H. Immunomodulatory effects of human amniotic membrane-derived mesenchymal stem cells. J. Vet. Sci. 2012, 13, 23-31. 
13. Ryan, J.M.; Barry, F.; Murphy, J.M.; Mahon, B.P. Interferon- $\gamma$ does not break, but promotes the immunosuppressive capacity of adult human mesenchymal stem cells. Clin. Exp. Immunol. 2007, $149,353-363$.

14. Lin, J.Q.; Lin, C.Z.; Lin, X.Z.; Zeng, K.; Gao, Y.G. Construction of a bicistronic recombinant adenoviral vector for human interleukin-10 and enhanced green fluorescent protein expression in bone marrow mesenchymal stem cells. Chin. Med. J. 2012, 125, 102-108.

15. Min, C.K.; Kim, B.G.; Park, G.; Cho, B.; Oh, I.H. IL-10-transduced bone marrow mesenchymal stem cells can attenuate the severity of acute graft-versus-host disease after experimental allogeneic stem cell transplantation. Bone Marrow Transplant. 2007, 39, 637-645.

16. Mackay, A.M.; Beck, S.C.; Murphy, J.M.; Barry, F.P.; Chichester, C.O.; Pittenger, M.F. Chondrogenic differentiation of cultured human mesenchymal stem cells from marrow. Tissue Eng. 1998, 4, 415-428.

17. Tuan, R.S. Biology of developmental and regenerative skeletogenesis. Clin. Orthop. Relat. Res. 2004, 427, S105-S117.

18. Tew, S.R.; Murdoch, A.D.; Rauchenberg, R.P.; Hardingham, T.E. Cellular methods in cartilage research: Primary human chondrocytes in culture and chondrogenesis in human bone marrow stem cells. Methods 2008, 45, 2-9.

19. Pillai, C.K.; Sharma, C.P. Review paper: Absorbable polymeric surgical sutures: Chemistry, production, properties, biodegradability, and performance. J. Biomater. Appl. 2010, 25, 291-366.

20. Yamanaka, T.; Sawai, Y.; Hosoi, H. A new supporting material for fascia grafting during myringoplasty: Polyglycolic acid sheets. Otolaryngology 2013, 149, 342-344.

21. Erggelet, C.; Neumann, K.; Endres, M.; Haberstroh, K.; Sittinger, M.; Kaps, C. Regeneration of ovine articular cartilage defects by cell-free polymer-based implants. Biomaterials 2007, 28, 5570-5580.

22. Patrascu, J.M.; Kruger, J.P.; Boss, H.G.; Ketzmar, A.K.; Freymann, U.; Sittinger, M.; Notter, M.; Endres, M.; Kaps, C. Polyglycolic acid-hyaluronan scaffolds loaded with bone marrow-derived mesenchymal stem cells show chondrogenic differentiation in vitro and cartilage repair in the rabbit model. J. Biomed. Mater. Res. B 2013, 101, 1310-1320.

23. Barry, F.; Boynton, R.E.; Liu, B.; Murphy, J.M. Chondrogenic differentiation of mesenchymal stem cells from bone marrow: Differentiation-dependent gene expression of matrix components. Exp. Cell Res. 2001, 268, 189-200.

24. Kim, M.; Erickson, I.E.; Choudhury, M.; Pleshko, N.; Mauck, R.L. Transient exposure to TGF- $\beta 3$ improves the functional chondrogenesis of MSC-laden hyaluronic acid hydrogels. J. Mech. Behav. Biomed. Mater. 2012, 11, 92-101.

25. Mueller, M.B.; Fischer, M.; Zellner, J.; Berner, A.; Dienstknecht, T.; Prantl, L.; Kujat, R.; Nerlich, M.; Tuan, R.S.; Angele, P. Hypertrophy in mesenchymal stem cell chondrogenesis: Effect of TGF- $\beta$ isoforms and chondrogenic conditioning. Cells Tissues Organs 2010, 192, 158-166.

26. Tuan, R.S.; Chen, A.F.; Klatt, B.A. Cartilage regeneration. J. Am. Acad. Orthop. Surg. 2013, 21, 303-311.

27. Chung, C.; Burdick, J.A. Engineering cartilage tissue. Adv. Drug Deliv. Rev. 2008, 60, $243-262$. 
28. Mafi, R.; Hindocha, S.; Mafi, P.; Griffin, M.; Khan, W.S. Sources of adult mesenchymal stem cells applicable for musculoskeletal applications-A systematic review of the literature. Open Orthop. J. 2011, 5, 242-248.

29. Martins, A.A.; Paiva, A.; Morgado, J.M.; Gomes, A.; Pais, M.L. Quantification and immunophenotypic characterization of bone marrow and umbilical cord blood mesenchymal stem cells by multicolor flow cytometry. Transplant. Proc. 2009, 41, 943-946.

30. Augello, A.; Kurth, T.B.; de Bari, C. Mesenchymal stem cells: A perspective from in vitro cultures to in vivo migration and niches. Eur. Cells Mater. 2010, 20, 121-133.

31. Tormin, A.; Brune, J.C.; Olsson, E.; Valcich, J.; Neuman, U.; Olofsson, T.; Jacobsen, S.E.; Scheding, S. Characterization of bone marrow-derived mesenchymal stromal cells (MSC) based on gene expression profiling of functionally defined MSC subsets. Cytotherapy 2009, 11, 114-128.

32. Bassi, G.; Pacelli, L.; Carusone, R.; Zanoncello, J.; Krampera, M. Adipose-derived stromal cells (ASCs). Transfus. Apher. Sci. 2012, 47, 193-198.

33. Yu, G.; Wu, X.; Dietrich, M.A.; Polk, P.; Scott, L.K.; Ptitsyn, A.A.; Gimble, J.M. Yield and characterization of subcutaneous human adipose-derived stem cells by flow cytometric and adipogenic mRNA analyzes. Cytotherapy 2010, 12, 538-546.

34. Buhring, H.J.; Treml, S.; Cerabona, F.; de Zwart, P.; Kanz, L.; Sobiesiak, M. Phenotypic characterization of distinct human bone marrow-derived MSC subsets. Ann. N. Y. Acad. Sci. 2009, $1176,124-134$.

35. Gong, X.; Sun, Z.; Cui, D.; Xu, X.; Zhu, H.; Wang, L.; Qian, W.; Han, X. Isolation and characterization of lung resident mesenchymal stem cells capable of differentiating into alveolar epithelial type II cells. Cell Biol. Int. 2014, 38, 405-411.

36. Moscoso, I.; Centeno, A.; Lopez, E.; Rodriguez-Barbosa, J.I.; Santamarina, I.; Filgueira, P.; Sanchez, M.J.; Dominguez-Perles, R.; Penuelas-Rivas, G.; Domenech, N. Differentiation "in vitro" of primary and immortalized porcine mesenchymal stem cells into cardiomyocytes for cell transplantation. Transplant. Proc. 2005, 37, 481-482.

37. Jung, Y.K.; Kim, G.W.; Park, H.R.; Lee, E.J.; Choi, J.Y.; Beier, F.; Han, S.W. Role of interleukin-10 in endochondral bone formation in mice: Anabolic effect via the bone morphogenetic protein/Smad pathway. Arthritis Rheumatol. 2013, 65, 3153-3164.

38. Erggelet, C.; Endres, M.; Neumann, K.; Morawietz, L.; Ringe, J.; Haberstroh, K.; Sittinger, M.; Kaps, C. Formation of cartilage repair tissue in articular cartilage defects pretreated with microfracture and covered with cell-free polymer-based implants. J. Orthop. Res. 2009, 27, 1353-1360.

39. Bedi, A.; Feeley, B.T.; Williams, R.J., 3rd. Management of articular cartilage defects of the knee. J. Bone Jt. Surg. Am. 2010, 92, 994-1009.

40. Charlton, D.C.; Peterson, M.G.; Spiller, K.; Lowman, A.; Torzilli, P.A.; Maher, S.A. Semi-degradable scaffold for articular cartilage replacement. Tissue Eng. A 2008, 14, 207-213.

41. Patrascu, J.M.; Freymann, U.; Kaps, C.; Poenaru, D.V. Repair of a post-traumatic cartilage defect with a cell-free polymer-based cartilage implant: A follow-up at two years by MRI and histological review. J. Bone Jt. Surg. Br. 2010, 92, 1160-1163. 
42. Shi, J.; Zhang, X.; Zeng, X.; Zhu, J.; Pi, Y.; Zhou, C.; Ao, Y. One-step articular cartilage repair: Combination of in situ bone marrow stem cells with cell-free poly(L-lactic-co-glycolic acid) scaffold in a rabbit model. Orthopedics 2012, 35, e665-e671.

43. Wegener, B.; Schrimpf, F.M.; Pietschmann, M.F.; Milz, S.; Berger-Lohr, M.; Bergschmidt, P.; Jansson, V.; Muller, P.E. Matrix-guided cartilage regeneration in chondral defects. Biotechnol. Appl. Biochem. 2009, 53, 63-70.

44. Siclari, A.; Mascaro, G.; Gentili, C.; Cancedda, R.; Boux, E. A cell-free scaffold-based cartilage repair provides improved function hyaline-like repair at one year. Clin. Orthop. Relat. Res. 2012, 470, 910-919.

45. Erickson, I.E.; van Veen, S.C.; Sengupta, S.; Kestle, S.R.; Mauck, R.L. Cartilage matrix formation by bovine mesenchymal stem cells in three-dimensional culture is age-dependent. Clin. Orthop. Relat. Res. 2011, 469, 2744-2753.

46. Gerter, R.; Kruegel, J.; Miosge, N. New insights into cartilage repair-The role of migratory progenitor cells in osteoarthritis. Matrix Biol. 2012, 31, 206-213.

47. Koelling, S.; Kruegel, J.; Irmer, M.; Path, J.R.; Sadowski, B.; Miro, X.; Miosge, N. Migratory chondrogenic progenitor cells from repair tissue during the later stages of human osteoarthritis. Cell Stem Cell 2009, 4, 324-335.

48. Kurz, B.; Lemke, A.K.; Fay, J.; Pufe, T.; Grodzinsky, A.J.; Schunke, M. Pathomechanisms of cartilage destruction by mechanical injury. Ann. Anat. 2005, 187, 473-485.

49. Schulze-Tanzil, G. Activation and dedifferentiation of chondrocytes: Implications in cartilage injury and repair. Ann. Anat. 2009, 191, 325-338.

50. Wassilew, G.I.; Lehnigk, U.; Duda, G.N.; Taylor, W.R.; Matziolis, G.; Dynybil, C. The expression of proinflammatory cytokines and matrix metalloproteinases in the synovial membranes of patients with osteoarthritis compared with traumatic knee disorders. Arthroscopy 2010, 26, 1096-1104.

51. John, T.; Muller, R.D.; Oberholzer, A.; Zreiqat, H.; Kohl, B.; Ertel, W.; Hostmann, A.; Tschoeke, S.K.; Schulze-Tanzil, G. Interleukin-10 modulates pro-apoptotic effects of TNF- $\alpha$ in human articular chondrocytes in vitro. Cytokine 2007, 40, 226-234.

52. Iannone, F.; de Bari, C.; dell'Accio, F.; Covelli, M.; Cantatore, F.P.; Patella, V.; Lo Bianco, G.; Lapadula, G. Interleukin-10 and interleukin-10 receptor in human osteoarthritic and healthy chondrocytes. Clin. Exp. Rheumatol. 2001, 19, 139-145.

53. Botha-Scheepers, S.; Watt, I.; Slagboom, E.; de Craen, A.J.; Meulenbelt, I.; Rosendaal, F.R.; Breedveld, F.C.; Huizinga, T.W.; Kloppenburg, M. Innate production of tumour necrosis factor $\alpha$ and interleukin 10 is associated with radiological progression of knee osteoarthritis. Ann. Rheum. Dis. 2008, 67, 1165-1169.

54. Mrosewski, I.; Jork, N.; Gorte, K.; Conrad, C.; Wiegand, E.; Kohl, B.; Ertel, W.; John, T.; Oberholzer, A.; Kaps, C.; et al. Regulation of osteoarthritis-associated key mediators by TNF $\alpha$ and IL-10: Effects of IL-10 overexpression in human synovial fibroblasts and a synovial cell line. Cell Tissue Res. 2014, 357, 207-223.

55. Liu, H.; Kemeny, D.M.; Heng, B.C.; Ouyang, H.W.; Melendez, A.J.; Cao, T. The immunogenicity and immunomodulatory function of osteogenic cells differentiated from mesenchymal stem cells. J. Immunol. 2006, 176, 2864-2871. 
56. Razmkhah, M.; Jaberipour, M.; Erfani, N.; Habibagahi, M.; Talei, A.R.; Ghaderi, A. Adipose derived stem cells (ASCs) isolated from breast cancer tissue express IL-4, IL-10 and TGF- $\beta 1$ and upregulate expression of regulatory molecules on T cells: Do they protect breast cancer cells from the immune response? Cell. Immunol. 2011, 266, 116-122.

57. Engela, A.U.; Baan, C.C.; Peeters, A.M.; Weimar, W.; Hoogduijn, M.J. Interaction between adipose tissue-derived mesenchymal stem cells and regulatory T-cells. Cell Transplant. 2013, 22, $41-54$.

58. Luz-Crawford, P.; Kurte, M.; Bravo-Alegria, J.; Contreras, R.; Nova-Lamperti, E.; Tejedor, G.; Noel, D.; Jorgensen, C.; Figueroa, F.; Djouad, F.; et al. Mesenchymal stem cells generate a $\mathrm{CD} 4{ }^{+} \mathrm{CD} 25^{+} \mathrm{Foxp}^{+}$regulatory $\mathrm{T}$ cell population during the differentiation process of $\mathrm{Th} 1$ and Th17 cells. Stem Cell Res. Ther. 2013, 4, doi:10.1186/scrt216.

59. Fahy, N.; de Vries-van Melle, M.L.; Lehmann, J.; Wei, W.; Grotenhuis, N.; Farrell, E.; van der Kraan, P.M.; Murphy, J.M.; Bastiaansen-Jenniskens, Y.M.; van Osch, G.J. Human osteoarthritic synovium impacts chondrogenic differentiation of mesenchymal stem cells via macrophage polarisation state. Osteoarthr. Cartil. 2014, 22, 1167-1175.

60. Gerstenfeld, L.C.; Cho, T.J.; Kon, T.; Aizawa, T.; Tsay, A.; Fitch, J.; Barnes, G.L.; Graves, D.T.; Einhorn, T.A. Impaired fracture healing in the absence of TNF- $\alpha$ signaling: The role of TNF- $\alpha$ in endochondral cartilage resorption. J. Bone Miner. Res. 2003, 18, 1584-1592.

61. Hess, K.; Ushmorov, A.; Fiedler, J.; Brenner, R.E.; Wirth, T. TNF $\alpha$ promotes osteogenic differentiation of human mesenchymal stem cells by triggering the NF- $\mathrm{B}$ signaling pathway. Bone 2009, 45, 367-376.

62. Lu, Z.; Wang, G.; Dunstan, C.R.; Chen, Y.; Lu, W.Y.; Davies, B.; Zreiqat, H. Activation and promotion of adipose stem cells by tumour necrosis factor- $\alpha$ preconditioning for bone regeneration. J. Cell. Physiol. 2013, 228, 1737-1744.

63. Mountziaris, P.M.; Dennis Lehman, E.; Mountziaris, I.; Sing, D.C.; Kasper, F.K.; Mikos, A.G. Effect of temporally patterned TNF- $\alpha$ delivery on in vitro osteogenic differentiation of mesenchymal stem cells cultured on biodegradable polymer scaffolds. J. Biomater. Sci. Polym. Ed. 2013, 24, 1794-1813.

64. Langen, R.C.; Schols, A.M.; Kelders, M.C.; Wouters, E.F.; Janssen-Heininger, Y.M. Inflammatory cytokines inhibit myogenic differentiation through activation of nuclear factor- $\kappa \mathrm{B}$. FASEB J. 2001, 15, 1169-1180.

65. Heldens, G.T.; Blaney Davidson, E.N.; Vitters, E.L.; Schreurs, B.W.; Piek, E.; van den Berg, W.B.; van der Kraan, P.M. Catabolic factors and osteoarthritis-conditioned medium inhibit chondrogenesis of human mesenchymal stem cells. Tissue Eng. A 2012, 18, 45-54.

66. Murakami, S.; Lefebvre, V.; de Crombrugghe, B. Potent inhibition of the master chondrogenic factor $\operatorname{Sox} 9$ gene by interleukin-1 and tumor necrosis factor- $\alpha$. J. Biol. Chem. 2000, 275, 3687-3692.

67. Liu, X.; Xu, Y.; Chen, S.; Tan, Z.; Xiong, K.; Li, Y.; Ye, Y.; Luo, Z.P.; He, F.; Gong, Y. Rescue of proinflammatory cytokine-inhibited chondrogenesis by the antiarthritic effect of melatonin in synovium mesenchymal stem cells via suppression of reactive oxygen species and matrix metalloproteinases. Free Radic. Biol. Med. 2014, 68, 234-246. 
68. Hemeda, H.; Jakob, M.; Ludwig, A.K.; Giebel, B.; Lang, S.; Brandau, S. Interferon- $\gamma$ and tumor necrosis factor- $\alpha$ differentially affect cytokine expression and migration properties of mesenchymal stem cells. Stem Cells Dev. 2010, 19, 693-706.

69. Kehoe, O.; Cartwright, A.; Askari, A.; El Haj, A.J.; Middleton, J. Intra-articular injection of mesenchymal stem cells leads to reduced inflammation and cartilage damage in murine antigen-induced arthritis. J. Transl. Med. 2014, 12, doi:10.1186/1479-5876-12-157.

70. Liu, L.N.; Wang, G.; Hendricks, K.; Lee, K.; Bohnlein, E.; Junker, U.; Mosca, J.D. Comparison of drug and cell-based delivery: Engineered adult mesenchymal stem cells expressing soluble tumor necrosis factor receptor II prevent arthritis in mouse and rat animal models. Stem Cells Transl. Med. 2013, 2, 362-375.

71. Van Buul, G.M.; Villafuertes, E.; Bos, P.K.; Waarsing, J.H.; Kops, N.; Narcisi, R.; Weinans, H.; Verhaar, J.A.; Bernsen, M.R.; van Osch, G.J. Mesenchymal stem cells secrete factors that inhibit inflammatory processes in short-term osteoarthritic synovium and cartilage explant culture. Osteoarthr. Cartil. 2012, 20, 1186-1196.

72. Ojeda Ojeda, M.; Silva, C.V.; de, J.A.R.M.; Fernandez-Ortega, C. TNF $\alpha$ production in whole blood cultures from healthy individuals. Biochem. Biophys. Res. Commun. 2002, 292, 538-541.

73. Pfaffl, M.W. A new mathematical model for relative quantification in real-time RT-PCR. Nucleic Acids Res. 2001, 29, e45.

(C) 2014 by the authors; licensee MDPI, Basel, Switzerland. This article is an open access article distributed under the terms and conditions of the Creative Commons Attribution license (http://creativecommons.org/licenses/by/3.0/). 